\title{
Las ferrerías guipuzcoanas ante la crisis del siglo XVII
}

\author{
Álvaro Aragón RuANO \\ Universidad del País Vasco \\ alvaro.aragon@ehu.es
}

Recibido: 22 de marzo de 2010

Aceptado: 26 de octubre de 2011

\section{RESUMEN}

Durante mucho tiempo la historiografía ha considerado que la actividad siderometalúrgica vasca y guipuzcoana sufrió una manifiesta crisis durante el siglo XVII. Sin embargo, un análisis profundo de la documentación, más allá de los meros testimonios e indicios, demuestra que el XVII fue un período dinámico para la industria del hierro, en el que se produjeron innovaciones, transformaciones y reajustes continuos que permitieron al sector seguir manteniendo su prestigio en los mercados mundiales.

Palabras clave: ferrerías, Guipúzcoa, siglo XVII, transformaciones.

\section{The Guipuzcoan Ironworks and the Crisis of the Seventeenth Century}

\begin{abstract}
For a long time Basque historiography has considered that the ironworking industries suffered a clear crisis during the Seventeenth Century. However, a deepen analysis of the original sources, beyond mere testimonies and signs, shows that the Seventeenth Century was a dynamic period for the activity, with continuous innovations, changes and adjustments. This suggests that Guipuzcoan ironworking industries maintained its prestige around the world.
\end{abstract}

Key words: forges, Gipuzkoa, Seventeenth Century, changes. 


\section{INTRODUCCIÓN}

...están paradas e yermas las más de las ferrerías d'esta Provincia,...e se sustentaba en ellos mucho número de personas naturales que por faltar esto se an ydo fuera de su Patria por no allar en ella alimentos en que se entretener y sustentar, que es muy grande ynconbeniente por estar fundada esta Provincia y su principal sustento en el ser de las ferrerías y labor del fierro d'ellas, y su población con número de mucha gente para su defensa e guarda y seguridad del Reino. ${ }^{1}$

... a esta Provincia viniera a subir tanto el coste de un quintal de fierro que, si agora al presente los que tratan en su labrança tienen muy poca y tenue ganançia, binieran a tener considerable pérdida, con lo qual les fuera fuerça alçar la mano de este trato y las herrerías jermarse y faltar y ausentarse con esto los naturales de esta Provinçia y quedar despoblada y hierma, sin defensa alguna para cualquiera ymvasión de enemigos. $^{2}$

Ambos textos fueron redactados por las Juntas Generales de Guipúzcoa, aunque median casi cincuenta años entre uno y otro: el primero de ellos fue enunciado en 1590 en un contexto en el que se pretendía que los navíos extranjeros cumpliesen con la obligación de manifestar su carga en el puerto de San Sebastián y de cargar hierro como producto de retorno; el segundo, por su parte, ha de situarse en 1639 en un contexto en el que el Señorío de Vizcaya pretendía establecer -como finalmente hizo-, a consecuencia del aumento de la presión de la fiscalidad real, nuevas imposiciones sobre la extracción de vena de Somorrostro. Podríamos poner muchos más ejemplos en un período que se extiende desde el siglo XVI hasta prácticamente el siglo XIX. Apreciamos dos contextos cronológicos diferentes, sobre cuestiones diferentes, si bien relacionadas, en las que claramente el discurso es el mismo, aunque la literatura pueda variar algo. En los dos casos se considera la industria siderúrgica la columna vertebral de la economía guipuzcoana, pieza esencial para garantizar la ocupación de sus habitantes y evitar la despoblación del territorio, contribuyendo así a la defensa de las fronteras frente al enemigo francés. Como se puede comprobar, las instituciones provinciales desarrollaron un elaborado discurso, siempre con tintes catastrofistas, que mantuvieron a lo largo del tiempo. Sin embargo, cabe preguntarse ¿qué hay de cierto en todo ello?, ¿era realmente tan penosa la situación de la actividad siderúrgica guipuzcoana y durante un período tan prolongado?.

Estos "síntomas" han sido interpretados por la gran mayoría de la historiografía como prueba irrefutable de las dificultades del sector en el contexto de la "crisis del siglo XVII". Tradicionalmente, la historiografía vasca ha venido sosteniendo que la industria del hierro durante los siglos XVII y XVIII estuvo sumida en una crisis de larga duración. Las principales causas a las que remiten los diferentes autores son siempre la irrupción desde principios del siglo XVII de la competencia extranjera y el retraso tecnológico de la industria vasca, que provocaron una progresiva pérdida de

1 Díez de Salazar, L. M. y Ayerbe Iríbar, M. R.: Juntas y Diputaciones de Guipúzcoa, San Sebastián, Diputación Foral de Gipuzkoa, 1990-2008, Tomo XI, pp. 51-52.

2 Ibidem, Tomo XXVII, p. 498. 
los mercados europeos y un incremento paulatino de las dificultades para mantener los mercados peninsulares e indianos ${ }^{3}$. En la mayoría de los casos se han extrapolado modelos generales al caso vasco y guipuzcoano, dando por hecho que la crisis del siglo XVII se dio con toda su crudeza en territorio vasco y en las diferentes actividades productivas ${ }^{4}$. Sin embargo, un análisis detallado y exhaustivo de parte de la documentación del siglo XVII nos permite matizar esas afirmaciones.

Fundamentalmente, cuatro son los argumentos que utilizan los mencionados autores: la disminución del número de ferrerías a partir de las décadas finales del siglo XVI, y en cualquier caso durante el siglo XVII, con respecto al siglo XVI, y la inexistencia de nuevas fundaciones; la pérdida de los tradicionales mercados europeos del hierro, a consecuencia de las guerras y conflictos diplomáticos internacionales del último cuarto del siglo XVI, y la sustitución de importaciones practicadas por diferentes países europeos; la competencia de los hierros extranjeros, que entre otras cuestiones provocó el estancamiento de los precios durante este período; y la ausencia de cambios en la productividad o "aumentos sensibles en la capacidad unitaria de producción" de las ferrerías durante dicho período ${ }^{5}$. Analicemos cada uno de los aspectos mencionados.

\section{LA SUPUESTA DISMINUCIÓN DEL NÚMERO DE FERRERÍAS}

Para el siglo XVII contamos con dos fuentes que nos permiten un acercamiento cuantitativo. Por un lado, está el Compendio Historial de Guipúzcoa que escribiera en 1625 Lope Martínez de Isasti ${ }^{6}$, de cuyo testimonio Carrión concluye que existían 124

3 Azpiazu Elorza, J. A.: Sociedad y vida social vasca en el siglo XVI. Mercaderes guipuzcoanos, San Sebastián, Kutxa, 1990, Tomo I, pp. 302; Bilbao, L. M.: "Trasnformaciones económicas en el País Vasco durante los siglos XVI y XVII", en VV.AA.: Historia del Pueblo Vasco, San Sebastián, 1978, T. II, pp. 111-143; Bilbao, L. M.: "La industria siderometalúrgica tradicional en el País Vasco (1450-1720)", Hacienda Pública Española, 108-109 (1987), pp. 47-63; Bilbao, L. M., Fernández de Pinedo, E.: "Auge y crisis de la siderometalurgia tradicional en el País Vasco (1700-1850)", en TedDE DE LoRCA, P. (ed.): La economía española al final del Antiguo Régimen, Vol. 2, Madrid, Alianza Editorial, 1982; CARRIÓN ARregUI, I. M.: La siderurgia guipuzcoana en el siglo XVIII, Bilbao, Universidad del País Vasco, 1991, pp. 100-107; FernÁndez DE PINEDo, E.: Crecimiento económico y transformaciones sociales del País Vasco (1100-1850), Madrid, Siglo XXI, 1974, pp. 29-33; Fernández Albadalejo, Pablo: La crisis del Antiguo Régimen en Guipúzcoa, 1766-1833. Cambio económico e historia, Madrid, Akal, 1975, pp. 52-65; GonzÁlez GonzÁLez, A. F.: La realidad económica guipuzcoana en los años de superación de la crisis económica del siglo XVII (1680-1730), San Sebastián, Diputación Foral de Gipuzkoa, 1994, pp. 206-212 y 255-277; URIARTE AYo, R.: Estructura, desarrollo y crisis de la siderurgia tradicional vizcaina (1700-1840), Bilbao, Universidad del País Vasco, 1988.

4 Sobre los problemas derivados de la extrapolación de modelos y paradigmas y sobre el debate en torno al impacto de las crisis del siglo XVII véase Aragón RuANO, A.: "Transformaciones económicas en el sector costero guipuzcoano central durante el siglo XVII", Manuscrits, 26 (2008), pp. 191-236.

5 AzPiazu Elorza: op.cit., (nota 3), p. 302; Fernández AlbadaleJo: op.cit., (nota 3), p. 60 y Bilbao: op.cit., (nota 3) p. 57.

6 Martínez de Isasti, L.: Compendio Historial de Guipúzcoa, Bilbao, La Gran Editorial Vasca, 1972, pp. 234-237. De todas formas, sospechamos que dicha relación no incluyó todas las ferrerías que existían en la época y así lo demuestra el hecho de que no aparezca la ferrería de Ugarteola, en 
establecimientos ${ }^{7}$. La segunda de las informaciones es un memorial elaborado por las instituciones provinciales en 1689, en el que el número de ferrerías se situaba en torno a los 82 establecimientos ${ }^{8}$. Estas cifras nos estarían hablando de un importante descenso, de en torno a un tercio de los establecimientos, que se habría producido en el período central del siglo XVII.

De todas formas, hay que ser cauteloso con los testimonios coetáneos y conscientes de que las autoridades provinciales y locales manipulaban su discurso, siempre catastrofista, como estrategia para conseguir sus metas ante la corona y las autoridades reales. Una muestra palpable de ello la encontramos en la ordenanza sobre el plantío de castaños que redactó en 1623 el concejo de Oyarzun, en cuyo preámbulo aseguraba que la despoblación del valle se había producido a consecuencia de "... averse perdido, y arruinado muchas de las Herrerias...”. Sin embargo, por varios testimonios sabemos que en esa fecha Oyarzun seguía conservando activas las nueve ferrerías mencionadas entre 1508 y 1514 y entre 1560 y 1588, aunque según Lope Martínez de Isasti, en 1625 cuatro de ellas eran mayores y cinco martinetes, que como veremos habían aumentado su producción. Más aún, en el siglo XVIII sólo seis de ellas continuaban en activo?.

1. Tabla: Número de ferrerías entre los siglos XV y XVIII

\begin{tabular}{|c|c|c|c|c|}
\hline Período & $\begin{array}{c}\text { Díez } \\
\text { de Salazar }{ }^{10}\end{array}$ & $\begin{array}{c}\text { Carrión } \\
\text { Arregui }^{11}\end{array}$ & $\begin{array}{c}\text { Fernández }^{11} \\
\text { Albaladejo }^{\mathbf{1 2}}\end{array}$ & Barcenilla $^{\text {13 }}$ \\
\hline Fines del siglo XV & 110 & & & \\
\hline 1548 & 117 & & 180 & \\
\hline 1581 & & & $170-180$ & \\
\hline 1625 & & 124 & $118-187$ & \\
\hline 1752 & & 93 & 73 & \\
\hline
\end{tabular}

Oyarzun, que, sin embargo, aparece mencionada en 1630 como ferrería y martinete. Archivo Municipal de Rentería (AMR), E, 7, III, 3, 1.

7 CARrión Arregui: op.cit., (nota 3), p. 123, nota núm. 29.

8 Archivo General de Gipuzkoa (AGG-GAO), JD IM 1/13/29.

9 "La consideración de la grande diferencia del estado del Valle, y Concejo de los tiempos passados al que tiene al presente de diminucion (sic), y peoría, nos obliga a pensar el modo, y forma de su restauración; que entonces tenia labrantes, y corrientes tantas Herrerías, que entretenian mas de ochocientos hombres de pelea, sin necesidad de salir de la Tierra ... y ahora ha venido a despoblarse, de suerte, que apenas se hallan en èl cuatrocientos hombres de pelea, y otros tantos, y mas Hijos propios del Valle, que están ausentes en otras Tierras, y Provincias, por averles faltado la comodidad de trabajar, y ganar, con que se sustentar, y esto va cada dia de mal en peor; con que esta patente el grandissimo daño, que dello se le sigue al Lugar, y juntamente al servicio de su Magestad, cuya causa, y ocasión ha sido averse perdido, y arruinado muchas de las dichas Herrerías, y destruido, y assolado mucha parte de los Montes, que eran el sustento de ellas,... ”. Archivo Municipal de Oiartzun (AMO), A, 6, 1, 6; C, 4, 2, 1 y C, 4, 3, 1; AGG-GAO, CO LEJ 164; y Díez DE SALAZAR, L. M.: Ferrerías guipuzcoanas. Aspectos socioeconómicos, laborales y fiscales (siglos XIV-XVI), San Sebastián, Kutxa, 1997, pp. 29-58; MARTíneZ DE IsASTI: op.cit, (nota 6), p. 234 y CARRIÓN ARREGUI: op.cit., (nota 3), pp. 127-128 y 134. 


\begin{tabular}{|c|c|c|c|c|}
\hline 1773 & & 103 & & \\
\hline 1776 & & 94 & & \\
\hline 1789 & & & & 64 \\
\hline 1802 & & 94 & & \\
\hline
\end{tabular}

Fuente: elaboración propia a partir de los datos aportados por los autores mencionados

Según algunos autores entre 1550 y 1620, momento en el que supuestamente se manifiestan las primeras dificultades, las informaciones directas son mucho más expresivas de las concretas dimensiones de la crisis del sector: los textos de época ya no hablan de ferrerías nuevas que se edifican o de antiguas que se remodelan; al contrario, dan con frecuencia pruebas de que algunas están inactivas y de que otras se van destruyendo ${ }^{14}$. Pues bien, hemos tenido la oportunidad de localizar documentalmente al menos quince nuevas construcciones, reedificaciones o intentos de construcción de ferrerías entre 1570 y 1620 . Más aún, en el período que va desde los años cuarenta a los años noventa del siglo XVII encontramos nuevos intentos y construcciones, aunque no tan numerosos como en el período anterior ${ }^{15}$. Únicamente durante la década de los años treinta no nos consta ninguna nueva fundación o renovación, coincidiendo con el momento álgido de la guerra entre España y Francia, que supuso el período de mayores dificultades para la mayor parte de los ámbitos de la economía guipuzcoana ${ }^{16}$, afectando también a la actividad siderúrgica. No es un caso aislado, puesto que como ha demostrado recientemente Carmen Ceballos Cuerno, también en Cantabria se produjeron numerosas edificaciones durante el siglo XVII; de hecho, el número de ferrerías en dicho territorio pasó de 28 en la primera mitad del siglo XVI a 36 en la segunda, manteniéndose dicha cifra durante la primera mitad del siglo XVII, mientras que en la segunda pasó a 38 ferrerías $^{17}$.

10 Díez de Salazar, L. M.: Ferrerías en Guipúzcoa (siglos XIV-XVI), San Sebastián, Haranburu, 1983, pp. 146 y 273.

11 Carrión Arregui: op.cit., (nota 3), pp. 124, 265-266 y 283-286.

12 Fernández Albaladejo: op.cit., (nota 3), p. 60. Este autor incluye las 70 fraguas que existían en Oñate hacia 1567.

13 Barcenilla, M. A.: La pequeña Manchester. Origen y consolidación de un núcleo industrial guipuzcoano. Errentería (1845-1905), Donostia, Diputación Foral de Gipuzkoa, 1999, pp. 101-102.

14 Bilbao: op.cit., (nota 3), p. 53.

15 Se ha de advertir que no se ha realizado un exhaustivo vaciado de la documentación notarial disponible en el Archivo Histórico Provincial de Gipuzkoa, sito en Oñate, que contiene los protocolos notariales de los partidos de Vergara, San Sebastián y Azpeitia, y en el Archivo General de Gipuzkoa, donde se custodian los del partido de Tolosa. Más que probablemente las cifras aportadas aumentarían de mediar dicha documentación.

16 Aragón Ruano: op.cit., (nota 4), pp. 201-236 y Alberdi Lonbide, X.: Conflictos de intereses en la economía maritima guipuzcoana durante la Edad Moderna, Vitoria, Universidad del País Vasco, 2006 (tesis doctoral inédita).

17 Ceballos Cuerno, C.: Arozas y ferrones: las ferrerias de Cantabria en el Antiguo Régimen, Santander, Universidad de Cantabria, 2001, pp. 22-59. Especialmente véase cuadro núm. 1 de la página 58. 
Dejando de lado la perspectiva cuantitativa, que, como se ha podido comprobar, puede llegar a distorsionar la realidad, nos parece interesante profundizar en aspectos cualitativos. Aún asumiendo el descenso del número de instalaciones durante el siglo XVII, lo que nos interesa saber es cuál fue la evolución de las que perduraron. Encontramos una prueba de la evolución que entre los siglos XVI y XVII sufrieron las ferrerías guipuzcoanas en Lope Martínez de Isasti. En la relación que aporta, de las 96 instalaciones que cita 37, es decir, en torno a un tercio, cuentan con martinete. Habitualmente, el frío análisis cuantitativo no permite valorar el impacto real de las innovaciones y transformaciones que fue experimentando la siderurgia guipuzcoana; sector tildado de anquilosado y tecnológicamente atrasado o arcaico ${ }^{18}$. Como señala Joel Mokyr ${ }^{19}$ para poner en práctica una nueva tecnología se debe producir una interacción entre el innovador y su entorno humano, formado por competidores, clientes, proveedores, autoridades o vecinos. Una de las principales condiciones para que una innovación sea asumida son la tolerancia y diversidad, puesto que en toda sociedad existen fuerzas estabilizadoras que protegen el status quo, y son estas reticencias las que se deben superar; los principales obstáculos para que una innovación triunfe son la tradición, la costumbre, la rutina y la adhesión al pasado. Además se han de tener en cuenta los costes sociales derivados de su aplicación, puesto que el cambio tecnológico conmociona el mercado laboral, altera el entorno físico, deja obsoletos el capital humano y físico, y reduce el excedente de productor de los competidores del innovador.

En el caso guipuzcoano el empleo de la energía hidráulica se remonta al menos a fines del siglo XIII, aunque no fue hasta mediados del siglo XV cuando aparece perfectamente arraigada en el ámbito vasco. A comienzos del siglo XVI surgieron los martinetes o ferrerías menores, también conocidas como tiraderas, cuya función esencial era la de estirar los tochos forjados en las ferrerías mayores. La introducción del martinete comportó la necesidad de ampliar el tamaño de la rueda de las ferrerías mayores y modificar el trazado general de las mismas. Finalmente, entre 1540 y 1570 se produjo la expansión del sistema genovés, que supuso la aplicación de sistemas hidráulicos más eficientes en la mecánica general de las ferrerías dotadas de martinete, acabando de esa forma por mecanizar todo el proceso productivo ${ }^{20}$. La documentación demuestra que durante este período la conversión de ferrerías mayores en menores y viceversa fue constante, tratando de adecuarse a las necesidades del mercado y de buscar la máxima rentabilidad ${ }^{21}$.

18 Jean Cantelaube ha puesto, recientemente, el acento en que el sistema directo no debe ser considerado arcaico, puesto que tuvo sus innovaciones. Además no perduró únicamente en los Pirineos, sino que siguió existiendo también en otros puntos de Europa. CANTElaube, J.: La forge à la catalane Dans les Pyrénées ariégeoises, une industrie à la montagne (XVIIe-XIXe siècle), Toulouse, Meridiennes, 2005, pp. 39-41 y 102-103.

19 Moкyr, J.: La palanca de la riqueza. Creatividad tecnológica y progreso económico, Madrid, Alianza Universidad, 1993, pp. 27-28, 194-195, 225.

20 BiLbao, L. M.: "Introducción y aplicaciones de la energía hidráulica en la siderurgia vasca, siglos XIII-XVII. Addenda et corrigenda a una versión historiográfica", Stvdia Historica. Historia Moderna, 5 (1987), pp. 67-75 у op.cit., (nota 3), p. 57.

${ }^{21}$ AGG-GAO, CO LEJ 176; AGG-GAO, CO LEJ 596; Archivo de la Real Chancillería de Valladolid 
2. Tabla: Ferrerías construídas, reconstruídas o intentadas construir en Guipúzcoa (1570-1700²2

\begin{tabular}{|c|c|c|c|c|}
\hline Fecha & Denominación & Propiedad & Localidad & Tipo de intervención \\
\hline 1575 & $\begin{array}{l}\text { Martín Ochoa de } \\
\text { Areztondo }\end{array}$ & Particular & Cestona & Nueva construcción \\
\hline 1576 & $\begin{array}{l}\text { Domingo de } \\
\text { Arriola }\end{array}$ & Particular & $\begin{array}{l}\text { Valle de Ermua } \\
\text { (Elgoíbar) }\end{array}$ & Nueva construcción \\
\hline $1579-1580$ & Ibarluce & Particular & Azpeitia & Nueva construcción \\
\hline 1583 & Areizterrezu & Particular & Aya & Reedificación \\
\hline 1587 & Olaberria & Particular & Legazpia & Reedificación \\
\hline 1587 & Mirandaola & Particular & Legazpia & Reedificación \\
\hline $1589-1590$ & Narruondo & Particular & Zumaya & Nueva construcción \\
\hline 1590 & $\begin{array}{l}\text { Martín Ibáñez de } \\
\text { Aquemendi }\end{array}$ & Particular & Azpeitia & Nueva construcción \\
\hline 1596 & Añarbe & Concejil & Rentería & Reedificación \\
\hline 1597 & Ibaizabal & $\begin{array}{l}1 / 2 \text { Concejil, } 1 / 2 \text { par- } \\
\text { ticular }\end{array}$ & $\begin{array}{l}\text { Placencia de las } \\
\text { Armas }\end{array}$ & Nueva construcción \\
\hline 1604 & Urriolaondo & Concejil & Beasain & Reedificación \\
\hline $1609-1612$ & Errotaberria & Particular & Segura & Nueva construcción \\
\hline 1622 & Fagollaga & Concejil & Hernani & Reedificación \\
\hline 1621 & Agaraiz & Particular & Amasa-Villabona & Reedificación \\
\hline $1624-1625$ & Zaldivia & Concejil & Zaldivia & Nueva edificación \\
\hline 1643 & $\begin{array}{l}\text { De Lorenzo de } \\
\text { Abendaño }\end{array}$ & Particular & Idiazábal & $\begin{array}{l}\text { Intento de Nueva } \\
\text { construcción }\end{array}$ \\
\hline 1643 & Altuna & Particular & Azpeitia & Nueva construcción \\
\hline 1695 & Picoaga & Particular & Hernani & Reedificación \\
\hline
\end{tabular}

ARCHV, Pleitos Civiles, Lapuerta, Olvidados, 576/4; AGG-GAO, CO MCI 132.

22 Archivo General de Simancas (AGS), Cámara de Castilla, Memoriales y Expedientes, L 445/104; AGS, Cámara de Castilla, Memoriales y Expedientes, 1453/110; AGS, Cámara de Castilla, Memoriales y Expedientes, L 497/141; AGS, Cámara de Castilla, Memoriales y Expedientes, L 548/362; AGS, Cámara de Castilla, Memoriales y Expedientes, L 675/16; AGS, Cámara de Castilla, Memoriales y Expedientes, L 675/16; ARCHV, Pleitos Civiles, Lapuerta, Fenecidos, C 172/1; AGS, Cámara de Castilla, Memoriales y Expedientes, L 669/254; AGS, Cámara de Castilla, Memoriales y Expedientes, L 770/215; DÍEZ DE SALAZAR, op.cit., (nota 9), pp. 60-62; Archivo Municipal de Hernani (AMH), C,5,III,2,6; AGG-GAO, CO UCI 323; DÍEZ DE SALAZAR: op.cit., (nota 1), Tomo XXXIII, p. 408; AGG-GAO, CO LCI 1109 y Archivo de la Casa Olazával, Leg. 9, núm. 21. La ferrería de Añarbe, en Rentería, ya existía desde 1503 y bajo propiedad concejil. 
Posteriormente, entre el último tercio del siglo XVI y el primer tercio del siglo XVII se perciben algunos cambios, sobre todo en la organización de la producción. Con la introducción del martinete se acabó estableciendo una división del proceso de trabajo entre las ferrerías mayores, dedicadas a la reducción del mineral y a la elaboración primaria del hierro, y las ferrerías menores, aplicadas a la transformación del producto primario salido de las primeras en hierros comerciales, semiacabados y manufacturados ${ }^{23}$. En realidad, se produce una concentración de las actividades, por lo que la mayor parte de las instalaciones pasa a contar con ferrería mayor y ferrería menor, que lógicamente estira el hierro tocho producido en las primeras. Un caso ilustrativo es el de las ferrerías de Agaraiz, en Villabona, reconstruidas en 1621 por doña Juana de Oquendo y Zandategui, hermana del almirante don Antonio de Oquendo, y los hijos de aquél, Juan y don Miguel de Oquendo -una mayor, que fabricaba hierro tocho, y otra menor, que achicaba el hierro labrado en la mayor-, y situadas junto a la vieja ferrería del mismo nombre ${ }^{24}$, que supusieron una importante inversión en un momento supuestamente de dificultades.

Por último, durante toda la segunda mitad del siglo XVII, de la antigua división de trabajo entre ferrerías mayores y ferrerías menores o martinetes, se pasó a una integración total del proceso productivo. Primero se fueron extendiendo las cearrolas, como declaraba Bernardo Villarreal de Bérriz en su Máquinas hidráulicas el año $1736^{25}$. La aparición de las zearrolas, a lo largo de la segunda mitad del siglo XVII y comienzos del siglo XVIII, respondió a un doble intento: por un lado, el de acabar con la división de trabajo, entre las mayores que fundían y las pequeñas que tiraban, reduciendo de esa forma el número de operarios y el consumo de carbón y sustituyendo dos ferrerías por una integral, $\mathrm{y}$, por otro, el de mejorar los rendimientos a través de la fundición de coladas mayores ${ }^{26}$. Sin embargo, ello supuso la pérdida de calidad de los productos, lo que obligó a reducir el tamaño de la colada de 20 arrobas a 5, bajo la fórmula de las tiraderas, que dieron continuidad a la solución integral aunque con menores

23 Bilbao: op.cit., (nota 3), p. 57.

24 AGG-GAO, CO UCI 323.

25 “...desde fines del siglo pasado dieron en ponerlas mayores, a las que llaman Cear-olas, que funden y tiran, sin valerse de las ferrerías menores, labrando un hierro muy grueso de dos arrobas y media, y mas cada barra: y aun todavia ay algunas herrerias de estas; pero las mas se han reducido a Herrerias menores, en que hacen fundiciones de a cinco arrobas, y tiran las barras de buena proporcion, porque siendo los mazos menores, que en Cear-olas, y todo no tan torpe, ni fuerte, se hace todo con mas curiosidad: y el aver dexado el antiguo modo de labrar tocho, ha sido porque el hierro no era tan bueno, y después que se ha establecido esta forma, es mejor el hierro: a estas herrerias llaman tiraderas...". VILLAREAL DE BÉRRIZ, B.: Máquinas hidráulicas de molinos, y herrerias, y gobierno de los arboles, y montes de Vizcaya, Madrid, Antonio Marín, 1736, pp. 48-49.

26 Sabemos de la existencia de una ferrería zearrola ya en 1643 en la ferrería de Urbieta (Azpeitia). AGG-GAO CO LCI 1109. Ignacio Carrión sitúa zearrolas en Carquizano en la jurisdicción de Elgóibar en 1685, en Acelain en Soravilla-Andoain y en Lasarte a comienzos del siglo XVIII. CARRIón ARREGUI: op.cit., (nota 3), pp. 120-121. Fernández de Pinedo sitúa una evolución similar para el caso de Vizcaya, donde ya para 1651 se constata que en la Merindad de Durango en las ferrerías menores se empezaba a fundir y a tirar. FERNÁndez de Pinedo: op.cit., (nota 3), p. 33. 
dimensiones, siendo las que predominarán hasta la desaparición de las ferrerías en el siglo XIX ${ }^{27}$.

Podemos asegurar que en Guipúzcoa para finales del siglo XVII este proceso había dado lugar a una cierta especialización productiva, que estableció claras diferencias geográficas, traducida en la aparición de dos ámbitos de intereses, en ocasiones contrapuestos. Por un lado, se situarían los ferrones de la franja más meridional de la provincia, históricamente con un mayor vínculo con los mercados del interior peninsular, especializados en la industria de la transformación del hierro, dedicada a la elaboración de todo tipo de manufacturas férricas. A pesar de ser el sector que más directamente sufrió la competencia extranjera, pudo sobrevivir, merced a los costos añadidos que el hierro extranjero, procedente de la costa, tenía como consecuencia del transporte terrestre. Por otro lado, encontraríamos el resto del territorio, volcado al comercio marítimo, esencialmente dedicado a la fabricación de hierro en bruto o semielaborado. Esta realidad parece estar detrás de los dos proyectos de compañías que se trataron de establecer entre 1700 y 1701 para la comercialización del hierro vasco ${ }^{28}$.

Vemos por tanto que la historia de las ferrerías, a pesar de lo que se ha afirmado, no fue estática, los cambios fueron continuos, como resultado del interés y la necesidad de adecuarse a las nuevas realidades que iban surgiendo en los mercados. En ese proceso de cambio hubo, por supuesto, ganadores y perdedores, ferrerías que supieron amoldarse a los nuevos tiempos y que sobrevivieron o incluso salieron reforzadas, y ferrerías que no lo pudieron lograr y desaparecieron. Como asegura Mokyr ${ }^{29}$, las empresas con rutinas más adaptables prosperan y crecen a expensas de las que tienen menos éxito. En consecuencia, el siglo XVII fue para la industria siderometalúrgica guipuzcoana un período de continuos reajustes y reconversiones, pero al igual que lo había sido el siglo XVI y lo sería el siglo XVIII. Sobrevivieron las mejor dotadas por su situación geográfica ${ }^{30}$, las más fuertes financieramente o aquellas cuyos ferrones mostraron una mayor pericia.

En primer lugar, sobrevivieron aquellas en poder de las principales familias guipuzcoanas (Oquendo, Veroiz, Aldamar y Zarauz, Altuna, etc.), con alta capacidad

27 Arbide Elorza, I. y otros: Ferrerías en Legazpia, San Sebastián, Caja de Ahorros de Provincial, 1980, pp. 210-216. Luís María Bilbao propone un triple modelo integral: primero las ferrerías mayores, después las ferrería menores y, finalmente, las "nuevas ferrerías", consolidadas en el siglo XVIII, antes de 1750. BilbaO: op.cit., (nota 3), p. 60.

${ }_{28}$ El alto Oria (Cegama, Segura e Idiazábal), además de hierro en barras, exportaba a Castilla hierro hixuela y carretil. El alto Urola y Deva (Azpeitia, Vergara, Legazpia y Oñate) exportaban hierro semielaborado (sotil, cuadrado y rejas), clavos y herrajes (hierro cuchillero). Por su parte, de Elgóibar y Azpeitia no se exportaban productos manufacturados a Castilla, salvedad hecha de las ya mencionadas rejas de Azpeitia. Además de todo ello, en el mercado de Vergara se centralizaba parte del hierro en bruto labrado en la cuenca del río Deva y del hierro producido en el sector oriental de Vizcaya, en torno a Marquina y Durango. AlBerdi LonBide: op.cit., (nota 17) pp. 724-732 y "Proyecto de compañía de comercialización del hierro a principios del siglo XVIII", en Historia de Oñati: siglos XIV-XIX, Oñati, Ayuntamiento de Oñati-Kutxa, 1999, pp. 159-179.

29 MoKYr: op.cit., (nota 20), pp. 340 y 351.

30 Díez de Salazar: op.cit., (nota 10), p. 243. 
financiera y dueñas de varias instalaciones ${ }^{31}$. Si en un principio fueron Parientes Mayores y miembros de la administración los más interesados, a partir de los siglos XVI y XVII fue una nueva generación de comerciantes -algunos de ellos también con puestos en la administración real-, tratantes y exportadores de hierro la que se adueñó de las ferrerías, vendiéndolas posteriormente a pequeños inversores y ferrones. Como ya hemos demostrado ${ }^{32}$, existían estrechas relaciones entre las distintas actividades y territorios, a diferentes escalas, de forma que la especialización económica acontecida en un espacio geográfico concreto no era posible sin que en otros ámbitos se generasen otras especializaciones, que eran en conjunto complementarias. Una de las claves fue el continuo trasvase de capitales que se produjo: los capitales obtenidos en la actividad siderúrgica eran reinvertidos en ella o en otras actividades lucrativas como la pesca, el corso, la construcción naval, el comercio de bastimentos o la compra de bienes inmuebles, y viceversa, siempre en función de la realidad del mercado. Ello es lo que explica que hubiese ferrerías que no labraban durante uno o dos años, para posteriormente volver a retomar la actividad ${ }^{33}$. Las razones principales de la inactividad solían ser las reformas e introducción de innovaciones y los descalabros provocados por las crecidas de los ríos y la necesidad de reparar los principales elementos. En realidad, la historia de la mayor parte de las ferrerías guipuzcoanas estuvo jalonada por una larga lista de destrozos, periódicos arreglos y obras, que, sin duda, entraban dentro de las previsiones de los inversores y que no alteraban su interés hacia ellas, puesto que eran fácilmente cubiertas en uno o a lo sumo dos ejercicios ${ }^{34}$.

El ejemplo de la ferrería de Inturia es altamente ilustrativo. En el año 1543 se renovó completamente, pero tres años después las avenidas del río Leizarán se llevaron la presa, y años más tarde nuevamente. En 1552 el río se llevó el puente y en 1561 se gastó el uso mayor y hubo que construir uno nuevo ${ }^{35}$. En el mencionado año de 1543 se gastaron en la reparación 81 ducados; si tenemos en cuenta que durante ese período y hasta aproximadamente 1570 el quintal de hierro valió un ducado y que hacia 1537 la renta que se pagaba era de 40-60 quintales al año, lo cual suponía unos ingresos anuales de en torno a 40-60 ducados derivados del cobro de la renta de la

31 AZ, 322-18; Arbide ElorZa: op.cit., (nota 28), pp. 97-98.

32 ARAgÓn RuANo: op.cit., (nota 4), pp. 191-236. Nos parecen interesantísimas y acertadas las palabras de Jean-Phillipe Priotti sobre esta cuestión: “...la guerra favorece también a los empresarios vascos, y les permite, sobre todo entre 1580 y 1640, diversificar sus inversiones y reforzar su actividad comercial...Las funciones portuarias del País Vasco son múltiples e interactivas: construcción naval, industria del hierro, comercio y pesca, mercado de productos diversos y mercado financiero. Gracias a esta diversidad un sector de actividad puede eventualmente suplir las insuficiencias de los otros.". PRIOTTI, J.-P.: Bilbao y sus mercaderes en el siglo XVI. Génesis de un crecimiento, Bilbao, Diputación Foral de Bizkaia, 2005, pp. 140-142.

33 La ferrería Aramburu, en Oyarzun, estuvo a pleno rendimiento durante quince meses, entre 1574 y 1575 , produciendo en ese tiempo 1.200 quintales, tras lo cual estuvo un año parada, para retomar su actividad a razón de 500 quintales anuales. ARCHV, Pleitos Civiles, Lapuerta, Olvidados, 576/4 y Archivo Municipal de Legazpia (AML), 177/1.

34 En contra de esta opinión, Pablo Férnandez Albadalejo considera que la sola detención de una ferrería supone ya una gran pérdida por el deterioro que sufren cuando están inactivas. FERNÁNDEZ Albadalejo: op.cit., (nota 3), p. 63.

35 AGG-GAO CO ECI 185. 
ferrería, podemos decir, sin ningún género de dudas, que en el plazo de dos años se cubrieron las inversiones hechas en su renovación ${ }^{36}$. En todo caso, tampoco se debe caer en el error de generalizar, puesto que no todas las ferrerías serían igual de rentables, en función de la disponibilidad de vena, carbón y madera, agua, capital, etc.

En segundo lugar, perduraron, aunque parezca una perogrullada, las que a pesar de las dificultades, continuaron activas. Fueron éstas las que, una vez desaparecidas el resto de competidoras, se hicieron con el disfrute de los recursos y materias primas y con el control de los mercados anteriormente compartidos. En tercer lugar, subsistieron aquellas que contaron con facilidades en la explotación de los recursos, sobre todo forestales, destacando de entre ellas las ferrerías municipales. El fenómeno de las ferrerías municipales se extiende por todo el territorio guipuzcoano -encontramos ferrerías municipales en lugares como Beasain o Placencia de las Armas-, aunque es el ámbito oriental de la provincia, el limítrofe con Navarra, en el que más habitualmente se produce. La mayor parte de ellas comenzaron a construirse a finales del siglo $\mathrm{XV}$ y comienzos del siglo $\mathrm{XVI}^{37}$, aprovechando en muchos casos el triunfo de los homes buenos sobre los Parientes Mayores y ferrones, que hasta ese momento habían monopolizado, cuando no "usurpado", las riquezas forestales municipales, pieza esencial a partir de ahora para las finanzas municipales: el arrendamiento de las ferrerías municipales -junto al de molinos, carnicerías, montes, etc.- supondrá pingües ingresos para las arcas municipales, que así podrán hacer frente a los cada vez más voluminosos gastos, derivados de la complicación administrativa y de las exigencias militares de la corona ${ }^{38}$.

Las ferrerías municipales podían contar, a precios inmejorables, con las principales riquezas forestales de cada jurisdicción, sin que el resto pudiese competir con ellas y, lo que es más importante, tenían garantizado el abastecimiento, puesto que el arrendamiento incluía la provisión de leña para carbón, procedente de los montes concejiles. Entre los motivos que la villa de Hernani mostró en 1692 para una posible compra de las ferrerías de Ereñozu se manifestaba que “...siempre se conservan con mas cuidado y credito las que son de comunidades, como lo enseña la esperiencia ..." 39 . Efectivamente, no sólo el acceso a materias primas, sino incluso la capacidad financiera de los municipios guipuzcoanos -tampoco aquí se puede ni se debe generalizar-, permitiría a estas ferrerías y a sus arrendatarios estar más protegidos y sufrir en menor medida las dificultades del mercado, ocupando una posición privilegiada en él.

36 Ibidem. Años más tarde, entre 1575 y 1576, Catalina de Durango, viuda de Luis de Aguirre, hubo de hacer frente a los gastos derivados de una serie importante de obras en la ferrería Picoaga de Hernani, que junto a los gastos ordinarios ascendieron a 28.698 reales y 22 maravedís. Durante ese período la mencionada ferrería labró 1.237 quintales de hierro, que vendidos 400 de ellos a 23 reales y el resto a 24 reales, aportaron unos ingresos de 29.288 reales. Si comparamos el cargo y la data, observamos que finalmente en el bienio 1575-1576 obtuvo un beneficio y superávit en torno a los 590 reales. AGG-GAO, CO LEJ 26.

37 Fernández Albadalejo: op.cit., (nota 3), pp. 55-56.

38 Aragón Ruano, A.: El bosque guipuzcoano en la Edad Moderna: aprovechamiento, ordenamiento legal y conflictividad, San Sebastián, Sociedad de Ciencias Aranzadi, 2001, pp. 134-140 y DíEz DE SAlAZAR: op.cit., (nota 9), pp. 43-45.

$39 \mathrm{AMH}, \mathrm{C}, 5$, III, 2, 6. 
Hernani ponía el acento en que, con la compra, el concejo podría arrendar la ferrería y el aprovechamiento de los montes concejiles, “... a precio cierto, sauido y comun, evitando las inteligencias que se experimentan en perjuizio de la villa, entendiendose los dueños y ferrones de las demas herrerias sobre el precio de dichos montes...". Consideraba que su compra era imprescindible, sobre todo para evitar que la ferrería municipal de Fagollaga, metros más abajo, tuviese problemas con el abastecimiento del agua, por lo cual recomendaba que no mediase Real Facultad para realizarla. Este mismo ejemplo nos permite calibrar la repercusión económica que una ferrería podía tener en las finanzas municipales, ya que en el mencionado rol de motivos se calculaba que dicha ferrería de Ereñozu, con un valor de 6.000 ducados de plata, podría producir anualmente 200 ducados de vellón.

Durante el siglo XVII asistimos a una doble dinámica, que ya se venía produciendo en el siglo anterior: la erección de nuevas ferrerías municipales -alguna de las cuales era compartida con algún particular- y la adquisición o compra de un importante número de ferrerías particulares, para convertirlas en municipales. Esta realidad tiene también una doble lectura. Por un lado, demuestra las dificultades que algunas ferrerías o sus dueños y arrendatarios estaban sufriendo, pero por otro, lo atractivo de las instalaciones siderúrgicas para las instituciones y finanzas municipales. Durante toda la edad moderna fue clave la capacidad financiera y el acceso a las materias primas, y en ese ámbito las ferrerías municipales jugaban con ventaja ${ }^{40}$. Como se puede observar en la tabla 2 , durante el período que nos ocupa se erigen o reedifican al menos cinco ferrerías concejiles, todas ellas curiosamente entre 1595 y 1625.

Durante la segunda mitad del siglo XVI y todo el siglo XVII se perciben cambios importantes en las fórmulas de propiedad y explotación de las ferrerías. La propiedad de las ferrerías pasa a fraccionarse, es decir, si hasta mediados del siglo XVI pocas ferrerías comparten propiedad y la mayoría de ellas pertenecen a un solo propietario, a partir de la segunda mitad de la centuria es cada vez más habitual que la propiedad sea compartida por dos, tres o cuatro personas ${ }^{41}$. Algo similar ocurre con el arrendamiento y el régimen de explotación de las ferrerías, que durante el siglo XVII tiende a fraccionarse y atomizarse. De los arrendamientos analizados por Díez de Salazar ${ }^{42}$ para el siglo XVI sólo un 10’22 \% correspondían a ese modelo. Según el mismo autor este modelo venía dado por la división en la propiedad de las ferrerías, generalmente motivado por la falta de mayorazgo de ciertas familias y por la escasa capacidad pecuniaria de los arrendatarios. Ello, no obstante, parece contradecirse con el hecho, también constatado por el mismo autor, de que los arrendamientos llevados a cabo por un comerciante o un ferrón-comerciante son más habituales a medida que se acerca el siglo XVII y que la élite se va enriqueciendo y ampliando, tendiendo a

40 "Las ferrerias suelen estar o no corrientes según los caudales de sus dueños que lo necesitan prompto para anticipar el verano muchas prevenciones para trabaxarse el invierno y tambien consiste en si son buenos Administradores de esta su Hazienda como suzede en las de otra qualquiera calidad... ’. AHN, Consejos, 10859.

41 AGG-GAO, CO MEJ 1503.

42 Díez de Salazar: op.cit., (nota 10), pp. 237-239. 
acaparar todo el proceso de transformación del hierro ${ }^{43}$. Durante el siglo XVII, los arrendamientos se dividen en mitades, tercias e incluso sextas partes. Parece ser que este fenómeno se convirtió en algo más habitual durante el siglo XVIII, que Carrión vincula a la acumulación de bienes, propiedades y mayorazgos ${ }^{44}$. Esto provoca también la división de las labores siderúrgicas en turnos, generalmente distribuidas semanalmente ${ }^{45}$. También desde mediados del siglo XVI empezamos a encontrar un fenómeno que será común durante los siglos XVII y XVIII, denominado "aguachería", una fórmula de subarriendo por la que el ferrón, encargado de hacer acopio de los materiales, paga a los operarios una cantidad por quintal labrado y entrega al ferrón en concepto de renta un quintal de cada 10 o 12 labrados $^{46}$. Por último, desde finales del siglo XVI es cada vez más habitual que los ferrones arrienden y gestionen varias ferrerías a la vez ${ }^{47}$, lo cual les permite sin ninguna duda minimizar los riesgos y completar ingresos.

Durante el siglo XVII las factorías siderúrgicas se fueron convirtiendo también en caseríos, es decir, en unidades de explotación integrales, en las que se desarrollaban actividades agropecuarias e industriales ${ }^{48}$. Si bien la posesión de ferrerías iba en el siglo XVI asociada a la posesión y explotación de rebaños de vacas, como demuestran los casos de Oyarzun y los montes francos del Urumea, donde los dueños y arrendadores de seles y bustos eran dueños de ferrerías, en los siglos XVII y XVIII en algunas villas, como Segura o Idiazábal, la reorganización de los sectores siderúrgico y ganadero provocó que los operarios compaginaran la labor ferrona y la cría de ovejas o se dedicasen exclusivamente a la última. El desarrollo de la ganadería estante, gracias a la extensión de cultivos como el maíz, provocó, por un lado, modificaciones en la estructura de las unidades de explotación, convirtiendo los caseríos y las ferrerías en explotaciones integrales, y, por otro, indujo cambios en la cabaña ganadera guipuzcoana, en la que hasta entonces habían predominado el ganado vacuno y el porcino, cuyo peso específico disminuyó ante la expansión del ganado ovino, y en el régimen de explotación de los bosques, en los que los jarales comenzaron a retroceder a favor de los robles trasmochos, precisamente tratando de evitar los perjuicios que el ganado, sobre todo, vacuno infringía a los primeros y que repercutía en la disponibilidad de carbón para las ferrerías, como alertaba el licenciado Arnedo en 1662: "...lo peor es que las herrerias que se hicieron para que mirasen por los montes se

43 Ibidem, pp. 238-239.

44 CARrión Arregui: op.cit., (nota 3), pp. 203-205 y 211-221.

45 AGG-GAO, CO ECI 1073.

46 Ibidem, p. 212 y AGG-GAO CO MCI 145.

47 ARCHV, Pleitos Civiles, Lapuerta, Olvidados, 576/4 y AGG-GAO, CO LEJ 164.

48 Un ejemplo indiscutible de ello es el de la ferrería municipal de Olloquiegui, en Leizarán, perteneciente a los concejos de Berástegui y Elduayen. En 1599 Olloquiegui ya había iniciado ese proceso y se había convertido en un complejo industrial, pues contaba con ferrería mayor y menor o martinete, casa vivienda y molino. En 1613 el fenómeno se acentuó, puesto que contaba con ferrería mayor y menor, fundición y fragua, carboneras, molino, casa-habitación, albergue de ganado ( 80 ovejas, 20 cabras y 4 vacas mayores y menores), establo y lagar. DíEZ DE SALAZAR: op.cit., (nota 9), pp. 237-238 y AGG-GAO CO ECI 1003. 
an conbertido en casas de ganado que los destruyen..." "49. Este fenómeno será cada vez más habitual durante el siglo XVIII ${ }^{50}$.

3. Tabla: Renta anual en ferrerías del valle de Leizarán (quintales machos)

\begin{tabular}{|c|c|c|}
\hline Período & Resto & Olloquiegui \\
\hline 1537 & 40 & 60 \\
\hline 1570 & 60 & 100 \\
\hline
\end{tabular}

Fuente: AGG-GAO CO ECI 185.

4. Tabla: Renta anual en ferrerías del valle de Leizarán (ducados)

\begin{tabular}{|c|c|}
\hline Período & Cantidad \\
\hline $1587-1595$ & 100 \\
\hline $1597-1605$ & 215 \\
\hline $1605-1613$ & 350 \\
\hline
\end{tabular}

Fuente: AGG-GAO, CO ECI 1003.

5. Tabla: Renta anual en ferrerías guipuzcoanas

\begin{tabular}{|c|c|c|}
\hline Período & Localidad & Cantidad \\
\hline 1624 & Oyarzun & 200 ducados \\
\hline 1640 & Oyarzun & 214 ducados \\
\hline 1643 & Azpeitia & 200 ducados \\
\hline 1657 & Azpeitia & 200 ducados \\
\hline 1692 & Hernani & 200 ducados \\
\hline
\end{tabular}

Fuente: AGG-GAO CO LEJ 596, CO LEJ 925, CO LCI 1009, CO MEJ 1299 y AMH, C, 5, III, 2, 6.

Tal vez, todo ello fue lo que provocó el aumento de las rentas, precisamente desde el último tercio del XVI hasta la década de los años veinte del siglo XVII. En el caso del valle de Leizarán ello repercutió en el cobro de las festaburnías que pagaban los arrendatarios a los concejos de Berastegui y Elduayen, las cuales pasaron de 6 quin-

49 Aragón Ruano, A.: La ganadería guipuzcoana en el Antiguo Régimen, Bilbao, UPV, 2009, pp. 221-228 y AMH, C, 5, I, 3, 4.

50 CArrión Arregui: op.cit., (nota 3), p. 209. 
tales en 1570 a 9 quintales en 1613. El aumento también es perceptible en los arrendamientos que pagaban a los propietarios de las ferrerías, entre 1570 y 1620, coincidiendo con una subida en el precio del hierro, que hasta la primera de las fechas había sido de un ducado por cada quintal ${ }^{51}$. Sin embargo, a partir de ese momento, parece que las mencionadas rentas permanecen estancadas durante toda la centuria, mientras que el precio del hierro llevó otros derroteros, lo cual sin duda benefició a los productores, que de esa forma pudieron obtener mayores márgenes de beneficio. Si durante los siglos XV y XVI la renta se pagaba en hierro o en hierro y dinero ${ }^{52}$, durante el siglo XVII vemos que las rentas comienzan a monetarizarse. En el siglo XVIII, esta tendencia se reafirma tanto en Vizcaya como en Guipúzcoa, aunque en algunos casos se paga en hierro, lo cual es interpretado por Carrión dentro del proceso de desvinculación del sector de los dueños, ya que el pago en especie evidencia la vinculación del propietario con la comercialización del hierro. Al parecer, las rentas en dinero oscilaron menos en el caso de las ferrerías particulares que en el caso de las municipales; dicha estabilidad se debió a la tendencia a la continuidad de los arrendamientos y a la posibilidad de compensar alzas o bajas por medio de otras prestaciones ${ }^{53}$.

Durante el período que va desde los siglos XV al XVIII el porcentaje más habitual fue el $10 \%$, es decir, el pago de 1 quintal por cada 10 labrados $^{54}$, sin embargo, en lugares como Azpeitia ${ }^{55}$, vemos que hay una cierta evolución, puesto que si durante el siglo XVI el coeficiente se mantuvo en 1/10 (10\%), entre 1628 y 1629 descendió a $1 / 12(8,5 \%)$ y finalmente en 1658 volvió a aumentar a un 1/11 (9\%). Durante el siglo XVIII los más habituales fueron el 10 y el $8{ }^{\prime} 5 \%{ }^{56}$. Según Díez de Salazar, en general, el sistema, lejos de beneficiar al dueño y propietario, beneficiaba a los arrendatarios, puesto que al fijarse la renta sobre un porcentaje de la producción, quedaba a salvo de la quiebra de accidentes, paradas, falta de materiales, etc. Sin embargo, la documentación parece contradecir esa afirmación. En las cuentas de las ferrerías mayor y menor y molinos de Errecalde y Berroeta, en Azpeitia, presentadas por Antonio Lapaza, arrendador de las mismas, -tomando como referencia el valor de 36 reales/quintal a los que estaba en el año 1627 el quintal de hierro en Guipúzcoa ${ }^{57}$-, se colige que en el año 1629, el cargo total ascendió a 3.501'5 reales y el descargo a 4.221'98 reales. Por tanto, este año hubo mayores pérdidas que ingresos, concretamente, 720 reales de pérdida, lógicamente, puesto que la ferrería había estado parada a consecuencia de las crecidas de agua, que ocasionaron importantes destrozos. Sin embargo, en el año 1630 el cargo total ascendió a 3.443 reales y el descargo a $1.935^{\prime} 88$ reales, lo que supone unos beneficios de 1.507' 12 reales, que permitieron cubrir ampliamente

\footnotetext{
51 AGG-GAO, CO ECI 185.

52 Díez de SAlazar: op.cit., (nota 10), p. 236.

53 CARrión Arregui: op.cit., (nota 3), pp. 214-215.

54 Díez de Salazar: op.cit., (nota 10), pp. 231-232.

55 Archivo Municipal de Azpeitia (AMAz), Expedientes judiciales, 1322-12 y AGG-GAO, CO

56 CARrión Arregul: op.cit., (nota 3), p. 212.

57 AGG-GAO, JD IM 2/23/15.
} MEJ 1299. 
las pérdidas del año anterior, lo cual nos lleva a concluir que, efectivamente, en condiciones normales y si no mediaba ninguna catástrofe natural, la actividad siderúrgica era rentable ${ }^{58}$.

El precio del contrato de arrendamiento sufrió un descenso a fines del siglo XV y hasta finales del siglo XVI permaneció estancado, momento en el que volvió a aumentar ${ }^{59}$. El caso de Azpeitia confirma que, como se puede observar en la tabla 5, las rentas se fosilizaron y estancaron durante el siglo XVII, beneficiando aún más a los arrendatarios. Una de las razones de ese estancamiento, más allá de posibles dificultades coyunturales que complicarían el cobro de las rentas, bien pudiera ser el absentismo de los propietarios, algo que ya fue denunciado en su día por Larramendi ${ }^{60}$. Desde la década de los años ochenta comienzan a subir nuevamente en algunos puntos de la geografía guipuzcoana, aunque en otros todavía no se elevarán hasta bien entrado el siglo XVIII. A comienzos de la segunda década de dicha centuria hay una reducción sensible, alcanzándose los mínimos del período. Durante la década de los cuarenta se produce un nuevo descenso que en algunos casos se prolonga hasta la siguiente década. A partir de los años sesenta se inicia un período de alza, momento en el que se dan los máximos del período, hasta los años ochenta y noventa ${ }^{61}$.

Decíamos líneas atrás que el aumento en los arrendamientos que pagaban los arrendatarios de las ferrerías del valle de Leizarán a sus propietarios, entre $1570 \mathrm{y}$ 1620 , coincidió con una subida en el precio del hierro. En el siglo XV se produjo una caída tendencial de los precios del hierro, aunque desde principios del XVI comenzaron a subir ${ }^{62}$. Durante el siglo XVI experimentaron un continuado aumento, al menos desde 1530, que Díez de Salazar sitúa en un $300 \%$ con respecto a los del siglo $\mathrm{XV}^{63}$. Según los datos aportados por el mismo autor, se percibe un crecimiento progresivo y moderado en el tramo central de la centuria, que alcanza sus mayores cotas a fines de la misma y se prolonga hasta las primeras décadas del siglo XVII. Prácticamente desde los años ochenta del siglo XVI hasta el año 1625 el precio del quintal de hierro macho (tocho) se mantiene en torno a los

58 AMAz, Expedientes judiciales, 1322-12.

59 DíEz de SAlazar: op.cit., (nota 10), pp. 239-240.

60 “...antiguamente los dueños de las herrerías vivian en sus casas solares cercanas a ella; y atendiendo por sí mismo y sus criados al manejo y gobierno de ellas, se hicieron grandemente poderosos. Hoy viven en los pueblos y arriendan a otros sus herrerías con mucho menoscabo de sus familias y grandes utilidades del los arrendatarios...". LARRAMEnd, M.: Corografía o Descripción general de la muy noble y muy leal Provincia de Guipúzcoa, Echávarri, Amigos del Libro Vasco, 1985, p. 197.

61 Carríon Arregui: op.cit., (nota 3), p. 220.

62 BilbaO: op.cit., (nota 3), p. 52.

63 Díez de Salazar: op.cit., (nota 10), pp. 351-362. 
30-36 reales ${ }^{64}$. Los datos aportados por Carrión ${ }^{65}$ y Alberdi confirman que hasta la década de los años veinte del siglo XVII los precios del hierro se mantuvieron altos, aunque estables ${ }^{66}$.

Entre los años 1625 y 1639 -en un período de carestía y malas cosechas, derivadas de fuertes inundaciones, pero también de aumento de la presión fiscal ${ }^{67}$-, sin embargo, los precios volvieron a subir, hasta los 48 reales, tasa establecida por el corregidor. Detrás de ello estaban las repercusiones de las devaluaciones monetarias practicadas por la monarquía y el período bélico entre 1635-1639, que enfrentó a Francia con España, y que tanto perjudicó a Guipúzcoa. Si comparamos los precios de los productos semielaborados entre 1625 y 1627, percibimos un aumento de hasta 14 reales, esto es, entre un 30 y un $40 \%$. Precisamente en 1627, coincidiendo con la publicación de la Real Pragmática de 14 de septiembre de 1627, que limitó el precio en 66 reales/quintal en Andalucía, lo cual suponía una pérdida de 15 reales por cada quintal para los tratantes vascos, la villa de Azpeitia envió un memorial al rey solicitando que el precio del hierro subiese en Castilla y Andalucía, puesto que estaba demasiado barato, no siendo rentable, a consecuencia de los gastos de transporte, salarios y vena, cuyos precios se habían elevado. Un año después, en 1628 Domingo de Cortaverria y Juan Martínez de Altuna, precisamente vecinos de Azpeitia, en su propio nombre y en el del resto de comerciantes de hierro hacia Andalucía, elevaron ante las Juntas Generales de Tolosa sus quejas, por los efectos de la Pragmática real que tasaba los precios del hierro en Sevilla. Se pidió al veedor de la fábrica de Plasencia de las Armas, Sebastián López de Mallea, que mediase ante el rey y solicitase el aumento del precio del hierro y acero en Sevilla, puertos de mar y en Castilla, y que dichos productos no se tasasen y se pudiesen vender libremente ${ }^{68}$.

Cizúrquil, Azpeitia y Hernani se quejaban de que labrar un quintal de hierro costaba más de los 48 reales/quintal en que el corregidor había establecido la tasa, puesto que los fletes y derechos de transporte hasta Sevilla ascendían a 33 reales, lo que suponía un precio final de 81 reales/quintal de 150 libras. Se solicitaba así mismo la tasación de los fletes a Sevilla, que hasta 1625 habían sido de 3'5 reales/quintal mayor de 150 libras en las naos grandes y de 5'5-6 reales/quintal en navíos pequeños y zabras. En el arancel que se estableció, el quintal de vena de la tierra valía 30

64 AGG-GAO, CO ECI 185; AGG-GAO, JD IM 2/21/18; AGG-GAO, JD IM 2/23/15; AMB, Registros de Concejo, L /0018, ff. 73 ro - 76 vo; AHPG, 2/3044, ff. 83 r y voo; AHPG, 2/3078, ff. 35 v 36 ro; AHPG, 2/3085, f. 51 ro; DíEz DE SAlazAR: Juntas y Diputaciones ...op.cit., Tomo XXVIII, p. 183.; ARCHV, Pleitos Civiles, Zarandona y Balboa, 3338/1; AZ, 230-2; AGG-GAO, CO LEJ 26; AHPG, 2/3128, ff. 46 ro -47 vo y AHN, Consejos, 10859.

65 CArrión Arregui, I. M.: "Los precios del hierro en Guipúzcoa durante los siglos XVII y XVIII: un buen indicador de la coyuntura del sector siderúrgico", Revista de Historia Económica, Año IX, núm. 3 (1991), pp. 481-499.

66 Alberdi Lonbide, X.: "La actividad comercial en torno a las importaciones de bastimentos o víveres en los siglos XVI-XVII, base del sistema económico de Gipuzkoa durante la Edad Moderna", Itsas-Memoria, 4 (1996), pp. 248-258.

${ }^{67}$ Carrión Arregur: op.cit., (nota 3), pp. 73-74 y Díez de Salazar, L. M.: El diezmo viejo y seco, o diezmo de la mar de Castilla (s. XIII-XVI). Aportación al estudio de la Fscalidad guipuzcoana), San Sebastián, Fundación Doctor Camino, 1983, pp. 25-64.

68 AGG-GAO, JD IM 2/23/15 y DÍEZ DE SALAZAR, op.cit., (nota 1), Tomo XXIII, p. 290. 
maravedís, mientras que el de Somorrostro el doble ${ }^{69}$. Rentería alegaba que el precio de materiales, jornales e instrumental se había elevado un tercio, como consecuencia de la devaluación de la moneda: villas como Rentería, Oyarzun, Irún, San Sebastián, Hernani y el resto de villas ferronas debían importar bastimentos desde Francia, pagados en moneda de plata, que el jornal de un hombre en moneda de vellón no alcanzaba a cubrir; debido a ello los jornales subieron un tercio de su valor, arrastrando consigo el precio del carbón y la vena, que costaban el doble ${ }^{70}$. No obstante, se percibe ya una cierta división de intereses en este asunto, puesto que Rentería solicita a las Juntas que no se modifique la tasación hecha por el corregidor, “...no atendiendo a conveniencias de quatro particulares que por sus granjerías andan procurando que Su Señoria se haga dueño de sus comodidades posponiendo las de su consideración; siendo así que remedian su daño con no comprar aquello que no an de ganar como quieren, siendo verdad que ganan en los preçios que agora está dispuesto, y no falta quien ruegue por el fierro dándole y vendiendo en plata a los mismos preçios que se vendía agora quatro años. "71.

Transcurrido el período de dificultades, aunque el enfrentamiento con Francia se prolongó hasta 1659 , abiertas la vías habituales de comercio e incluso establecido un nuevo Tratado de Conversa ${ }^{72}$, el precio volvió a remontar el vuelo, llegando a situarse en los 60 reales de vellón. De hecho, cuando en 1641, ante las necesidades de la corona, inmersa en el conflicto portugués y catalán, sin haber abandonado todavía el francés, el secretario Francisco de Quincoces, superintendente de las reales fábricas de armas de Guipúzcoa, intentó embargar todo el hierro producido en las ferrerías de la provincia y ponerle tasa, pretendiendo que se le diese a 44 reales/quintal, el hierro corría en toda la provincia a 66 reales/quintal ${ }^{73}$. A partir de la década de los sesenta del siglo XVII el precio se vuelve a estabilizar en torno a la mencionada cifra, aun-

69 La mayor parte de cuencas utilizaban la vena de Musquiz, pero existían importantes excepciones: en la cuenca del Oyarzun unas ferrerías labraban con vena de Músquiz y otras con vena de la tierra, mezclada con aquella, en Irún la mayor parte utilizaba vena de la tierra, en Villafranca, Segura, Cegama, Lazcano y Legazpia utilizaban vena de Lecamburu, y por último, las ferrerías del valle de Leizarán utilizaban exclusivamente vena de la tierra, concretamente de las veneras de Orín. DÍEZ DE SALAZAR, op.cit., (nota 1), Tomo III, pp. 151-154; AGG-GAO, CO ECI 117 y AGG-GAO CO MCI 259. Durante el siglo XVII asistimos a una intensificación de las explotaciones en Oyarzun, Cerain y Mutiloa, que permitieron incluso exportar vena a Francia, Navarra u Oñate, además de las cuencas limítrofes. Por tanto, se debe relativizar el impacto del conflicto en torno a la exportación de vena de Somorrostro, que tuvo como protagonistas a Vizcaya, Guipúzcoa, Navarra y Labort, puesto que su repercusión no fue la misma en todos los ámbitos geográficos. Para el caso de las minas de Lecamburu véase: DíEz DE SAlazAr: op.cit., (nota 1), Tomo XVIII, p. 271; Tomo XXII, pp. 91, 93, 146, 220-221; Tomo XXIII, pp. 221-223, 346, 355; Tomo XXVI, pp. 2, 13 y 498; Tomo XXVIII, p. 293; AGG-GAO, CO ECI 117; Fernández Albadalejo: op.cit., (nota 3), p. 61. Para el caso de Oyarzun consúltese: AGG-GAO CO LCI 1326; AGG-GAO CO MCI 2042 y ARCHV, Pleitos Civiles, Alonso Rodríguez, Olvidados, 101/1.

70 Sobre la evolución del precio de la leña para carbón y su repercusión véase: ArAGÓN RUANO, A.: "Retroceso forestal, desamortizaciones y atraso tecnológico en la industria guipuzcoana del hierro durante el Antiguo Régimen”, Obradoiro de Historia Moderna, 18 (2009), pp. 119-149.

71 Díez de Salazar: op.cit., (nota 1), Tomo XXIII, p. 298 y 380-381; AGG-GAO, JD IM 2/23/15 y AMB, Registros de Concejo, L/0018, ff. 73 r $^{\circ}-76 v^{\circ}$.

72 Alberdi Lonbide: op.cit., (nota 17)

73 Díez de Salazar: op.cit, (nota 1), Tomo XXVIII, pp. 182-183. 
que existen diferencias regionales, que perdura hasta la década de los años veinte del siglo XVIII. En la década de los años cuarenta del siglo XVIII parece producirse un ligero descenso, pero desde los años cincuenta la subida es imparable hasta finales de la centuria, situándose en torno a los 80 reales de vellón ${ }^{74}$. Insistimos nuevamente en que los precios del hierro tuvieron una evolución muy diferente a las rentas, lo cual benefició a los ferrones. De las palabras de Rentería, además, bien se podría concluir que algunos tratantes y comerciantes estaban haciendo su agosto, a pesar del recorte de márgenes, como demuestra magníficamente García Fuentes ${ }^{75}$.

\section{LA PÉRDIDA DE MERCADOS: LA EXPORTACIÓN DE HIERRO GUIPUZCOANO Y LA IMPORTACIÓN DE HIERRO EXTRANJERO}

No seremos nosotros quienes neguemos la importancia de las importaciones de hierro extranjero, pero sí su repercusión y competencia con respecto al hierro vasco ${ }^{76}$. En primer lugar, porque como la mayoría de autores reconoce la política proteccionista de la corona protegió al hierro vasco, sobre todo en la propia península y en las Indias. En segundo lugar, porque el hierro forjado vasco seguía siendo insustituible para determinados usos, especialmente en la industria naval, de la herramienta y la ornamentación ${ }^{77}$. A ello se debe sumar la existencia de un mercado propio para los productos forjados vascos, que no será realmente puesto en peligro hasta el último cuarto del siglo XIX, cuando, ante la evidencia, las ferrerías tradicionales deberán paulatinamente dejar su lugar a otro tipo de sistemas. Como bien apunta Luís María Bilbao el establecimiento de altos hornos que dirigieran su producción al mercado español no será rentable hasta 1848 , lo que unido a la falta de calidad de los productos de acero y hierro colado hasta la aparición del método Bessemer, explica la tardanza de la aplicación de la industrialización moderna en el ámbito siderúrgico ${ }^{78}$.

Las últimas investigaciones están demostrando lo errático de los postulados que defienden la pérdida de mercados. En el caso de la exportación de hierro vasco hacia Inglaterra, recientemente se ha demostrado que la exportación desde el área cantábrica de hierro en lingotes no descendió en la primera mitad del siglo XVII, a pesar

74 CArrión Arregui: op.cit., (nota 3), pp. 272-278.

75 García Fuentes, L.: Sevilla, los vascos y América. Las exportaciones de hierro y manufacturas metálicas en los siglos XVI, XVII y XVIII, Bilbao, Fundación BBV, 1991, 49-102 y 156-180.

76 En un discurso que ya se empezaba a hacer habitual desde mediados del siglo XVI las Juntas de Motrico manifestaban que “...de diez años a esta parte a benido en gran disminuyçion (el comercio), a cuya causa se an parado muchas herrerias que no labran y se ban deshaçiendo por el poco espediente que ay del fierro que se despide, eçeto para Andaluçia...”. Dítz DE SALAZAR: op.cit., (nota 1), Tomo XII, pp. 426-427.

77 "En el segmento cualificado del mercado siderúrgico, los productos de las nuevas tecnologías, por baratos que fuesen, no podian competir con los hierros producidos por el sistema directo, dado que su sustitución no era ni técnicamente posible ni económicamente rentable”. BILBAo: op.cit., (nota 3), p. 56.

78 Bilbao, L. M.: “La primera etapa de la industrialización en el País Vasco, 1800-1880: cambio tecnológico y estructura de la industria siderúrgica”, en Fernández de Pinedo, E., Hernández Marco, J. L. (ed.): La industrialización del norte de España, Barcelona, Crítica, 1988, pp. 243-245. 
de la competencia del hierro sueco, y seguía activa a la altura de $1650^{79}$. Las exportaciones de hierro hacia Francia ${ }^{80}$ y Holanda ${ }^{81}$, como retorno de las importaciones de bastimentos, no se interrumpieron entre fines del siglo XVI y durante el siglo XVII, puesto que los importadores extranjeros procedieron a extraer la mayor parte de su valor en hierro. Estas exportaciones continuaron durante el período de irrupción del hierro de Lieja, sobre lo que insistiremos posteriormente. Los productos estrella eran los semielaborados, sobre todo el hierro sotil, aunque también encontramos partidas de carretil, planchuela y cuadrado, mientras que los productos manufacturados eran residuales.

Una cuestión que se olvida en demasiadas ocasiones es la creciente demanda desde la propia península. La demanda desde Guipúzcoa fue importante durante el período, sobre todo por el desarrollo de actividades como la industria naval o la industria armamentística, que gozaron de una buena salud ${ }^{82}$. Desde los años noventa del siglo XVI y definitivamente desde el reinado de Felipe III, Madrid se convirtió en la capital, lo que provocó un crecimiento inusitado de su población durante todo el siglo XVII y de la demanda de productos para su abastecimiento. Los escasos datos que sobre ello encontramos nos hablan de lucrativas empresas dedicadas abastecimiento, vía terrestre, de productos férricos vascos en los mercados madrileños, cada uno de cuyos miembros podían obtener beneficios anuales de cerca de 1.000 ducados $^{83}$. En este período parece así mismo que se intensificó la llegada de hierro, transformado y sin transformar, y de pescado guipuzcoanos a la Meseta sur, a cambio de sedas toledanas y otros textiles ${ }^{84}$. También la propia Sevilla, Cádiz y Andalucía fueron focos de demanda importante, no sólo para su reexportación a América, sino para consumo

79 Grafe, R.: Entre el mundo Ibérico y el Atlántico. Comercio y especialización regional 15501650, Bilbao, Diputación Foral de Bizkaia, 2005, pp. 118-123. Según estimaciones de los comerciantes de San Sebastián en 1687, los mercaderes ingleses retornaban anualmente 10.000 quintales de hierro guipuzcoano. AGG-GAO, JD IM 2/22/48.

80 Alberdi Lonbide: op.cit., (nota 69), pp. 248-251 y Alberdi Lonbide, X., Aragón Ruano, A.: "Le commerce du fer basque et des produits alimentaires français dans les ports du Guipúzcoa à la fin du XVIe et dans le première moitié du XVIIe siècle", en PriotTI, J.-P., SAUPIN, G.: Le commerce atlantique franco-espagnol. Acteurs, négoces et ports (XVe-XVIIIe siècle), Rennes, Presses Universitaires, 2008, pp. 215-231.

81 Díez de Salazar: op.cit., (nota 1), Tomo XXVIII, p. 485-486 y Priotti, op.cit., (nota 34), pp. 136-144. Este autor afirma que "...en lo que concierne al sector industrial, hemos visto anteriormente que su producción no parecía derrumbarse, ni a finales del siglo XVI ni, incluso, a principios del siglo siguiente. La capacidad de satisfacer la demanda interior (construcciones navales, fabricación de armas) y exterior (Portugal, América) no da de ello una prueba tangible...".

82 Odriozola, L.: Construcción naval en el País Vasco, siglos XVI-XX. Evolución y análisis comparativo, Donostia, Diputación Foral de Gipuzkoa, 2002; Carrión ArreguI, I. M.: "Artesanos, manufacturas y precios en la Gipuzkoa del siglo XVI", en Díaz de Durana, J. R. (ed.): La lucha de bandos en el País Vasco: de los Parientes Mayores a la Hidalguía Universal. Guipúzcoa, de los bandos a la Provincia (siglos XIV a XVI), Bilbao, UPV, 1998, pp. 493-522 y FernándeZ Albadalejo: op.cit., (nota 3), p. 59.

83 AGG-GAO, CO MCI 1798.

84 Rodríguez de Gracia, H.: "Relaciones comerciales en el siglo XVII: hierro guipuzcoano, cerrajería de Mora (Toledo) y seda toledana", Boletín de la Real Sociedad Bascongada de Amigos del País, LVIII, 2 (2002), pp. 335-376. 
propio, como demuestra la formación de numerosas compañías, entre 1600 y $1635^{85}$. Por último, entre 1580 y 1668 Portugal formó parte del entramado de la Corona hispánica, siendo Lisboa y Oporto centros comerciales importantes, hasta los que llegaba el hierro vasco, directamente o a través de Galicia ${ }^{86}$, no sólo para consumo propio y redistribución por todo el territorio, sino también para su reexportación hacia tierras americanas.

Sin duda, el principal mercado de los productos siderometalúrgicos vascos, tanto semielaborados como elaborados, durante el siglo XVII serán las Indias, sobre todo por vías ilegales y de contrabando. Lutgardo García Fuentes alerta de que los datos aportados por los registros legales no muestran la realidad, y achaca esta distorsión a lo incompleto y fragmentario de la documentación y a la intensificación del tráfico ilegal, esencialmente por el río de la Plata. Curiosamente, las cifras más bajas se producen entre 1610 y 1660, momento álgido del contrabando, tanto en los puertos peninsulares como en América, hasta la aparición de los navíos de registro ${ }^{87}$. El establecimiento de compañías para la exportación de hierros vascos a América, desde el último cuarto del siglo XVI y durante todo el siglo XVII, fueron negocios rentables y lucrativos, aunque dentro de una red y diversidad de operaciones y negocios ${ }^{88}$. La principal puerta de entrada del hierro guipuzcoano en Indias fueron los puertos portugueses, hasta el estallido de la rebelión en 1640, momento a partir del cual San Sebastián se convirtió en una de las plazas más importantes de armamento de expediciones legales o ilegales a Indias, aprestadas con capital local y extranjero ${ }^{89}$. El tráfico ilegal con Indias venía desarrollándose desde la primera mitad del siglo, fortalecido a raíz de la fase decadente que experimentó la Carrera de Indias a partir de los años veinte del siglo XVII. Esta situación se extendió hasta la década de los sesenta, cuando arrancó una nueva fase de crecimiento, atestiguada por el aumento de los envíos legales de hierro vasco a Indias. De hecho, García Fuentes comprueba la evolución alcista experimentada por las exportaciones legales de hierro a Indias a partir de la década de los sesenta ${ }^{90}$. Esta disminución del tráfico ilegal probablemente fue consecuencia de la regularización de las concesiones de permisos de navíos de registro ${ }^{91}$.

85 AGG-GAO CO LCI 1109; AHPG, 2/3044, ff. 83 r $^{\circ}$ y v $^{\circ}, 175$ vo; 2/3078, ff. 35 v $^{\circ}-36$ ro; 2/3046, ff. $95 \mathrm{r}^{\mathrm{o}} \mathrm{y} \mathrm{v}^{\mathrm{o}}, 298 \mathrm{r}^{\mathrm{o}}-299 \mathrm{v}^{\mathrm{o}}$; 2/3051, ff. $122 \mathrm{r}^{\mathrm{o}} \mathrm{y} \mathrm{v}^{\mathrm{o}}$; 2/3085, ff. 51 ro; 2/3055, ff. $45 \mathrm{r}^{\mathrm{o}}-48 \mathrm{v}^{\mathrm{o}}$; AHPG, 2/3047, ff. $156 \mathrm{r}^{\mathrm{o}}-158 \mathrm{v}^{\mathrm{o}}$.

86 Aragón Ruano, A., Alberdi Lonbide, X.: “....Lleben...las colas a las varrigas de los bufos...”: Balleneros guipuzcoanos en las "matanzas de ballenas de Galicia y Asturias durante los siglos XVI y XVII", Obradoiro de Historia Moderna, 15 (2006), pp. 77-111; BARKHAM, M.: "El comercio marítimo vizcaíno y guipuzcoano con el Atlántico peninsular (Asturias, Galicia, Portugal y Andalucía) y con los archipiélagos de Canarias y Madeira al principio de la Edad Moderna", Itsas-Memoria, 4 (1996), pp. 147-164 y Díez de Salazar: op.cit., (nota 3), Tomo XXVIII, p. 3

87 Díez de Salazar, Tomo XXV, p. 244.

88 García Fuentes, Lutgardo: op.cit., (nota 79), pp. 46-47, 81-102, 118-132, 136-142, 223-233.

89 Moutoukias, Z.: Contrabando y control colonial en el siglo XVII, Buenos Aires, Centro Editor de América Latina, 1988, pp. 131-132 y Oliva Melgar, J. M.: "Realidad y ficción en el monopolio de Indias: Una reflexión sobre el sistema imperial español en el siglo XVII", Manuscrits, 14 (1996).

90 García Fuentes, L.: El comercio español con América (1650-1700), Sevilla, Diputación Provincial de Sevilla, 1980, pp. 266-281 y op.cit., (nota 79), pp. 215-225.

91 Moutoukias: op.cit., (nota 92), pp. 131-132; MALAMUD RIKLES, Carlos: "El comercio directo 
Hubo dos momentos álgidos en torno a la polémica sobre la importación de hierros extranjeros: el primero durante la segunda década, en torno a la introducción del hierro de Lieja, el segundo en el último tercio del siglo XVII y la primera del siglo XVIII, a consecuencia de la llegada de hierro sueco. Ante las primeras protestas de aparición de hierros procedentes de Lieja, por entonces dentro del Imperio Alemán, aliado de España, ya en 1612 en Sevilla9 ${ }^{92}$, en 1619 y 1620, se prohibió la introducción de hierros extranjeros en la península, mientras que en 1621 se dictó la misma resolución para América, recibiendo nuevas sanciones en 1627 y $1629^{93}$. Se denunciaba la actitud de los tratantes de Vizcaya y Guipúzcoa, puesto que en sus prácticas especulativas, introducían y vendían hierro de Lieja, como si fuese vasco, lo cual perjudicaba al comercio del hierro y finalmente a la propia actividad siderúrgica, entre otras cuestiones, porque era un hierro "quebradiço" y de mala calidad, mientras que el hierro propio era "...de mayor bondad, seguridad, firmeza y duracion..." El mismo año 1620 las Juntas Generales de Zumaya pedían poner remedio a la introducción de hierro navarro en Guipúzcoa, para lo cual enviar un memorial al Consejo de Guerra, solicitando que no se pudiese introducir hierro navarro, mientras hubiese hierro de la tierra, y que en la construcción naval por cuenta de la corona y en la botería se utilizase sólo hierro de Guipúzcoa. Nuevamente se acudía al mismo discurso que relacionaba la introducción y competencia del hierro navarro al abandono de las ferrerías, la pérdida de población y la desprotección de las fronteras ${ }^{95}$. El problema era el mismo: la especulación y los abusos de los tratantes de hierro que compraban el hierro navarro, más barato, y lo vendían como si fuese de la tierra, como ocurría con el de Lieja. Dichas prohibiciones se mantuvieron durante todo el siglo XVII y las Juntas Generales insistían en cada una de las convocatorias en recordarlo ${ }^{96}$. La provincia hizo gestiones en 1622 para que el Consejo de Indias y el de Portugal prohibiesen la extracción de hierro extranjero a las colonias ${ }^{97}$.

En 11 de diciembre de 1656 Vizcaya y Guipúzcoa iniciaron pleito en el Consejo Real contra las naciones y cónsules extranjeros. Todavía en 1672 Guipúzcoa seguía insistiendo en el cumplimiento de las reales pragmáticas sobre prohibición de entrada de hierro extranjero en la península e Indias. En 1673 se confirmaron con Sobrecarta y nuevamente en 1675. Al principio del proceso las denuncias se multiplicaron en Sevilla y Veracruz, pero con el paso del tiempo se fueron relajando, de forma que en

de Europa con América en el siglo XVIII. Algunas consideraciones", en Quinto Centenario, 1 (1981) pp. 25-52; Consecuencias económicas del comercio directo francés en el espacio peruano (1698-1725), Madrid, Universidad Complutense, 1982, pp. 33-34; "Comercio Colonial del siglo XVIII visto como suma del comercio vía Andalucía y del comercio directo europeo", en Revista de Historia Económica, Año 1, núm. 2 (1983), pp. 307-322 y Cádiz y Saint Malo en el comercio colonial peruano (1698-1725), Cádiz, Diputación de Cádiz, 1986.

92 Díez de Salazar: op.cit., (nota 1), Tomo XVIII, pp. 392 y 418.

93 Bilbao, op.cit., (nota 3), p. 59; Fernández Albadalejo: op.cit., (nota 3), pp. 58-59 y Alberdi LONBIDE: op. cit., (nota 17), pp. 724-732.

94 AGG-GAO, JD IM 2/21/24.

95 Díez de Salazar: op.cit., (nota 1), pp. 257-258.

96 Ibidem, Tomo XXII- Tomo XXVIII.

97 Ibidem, Tomo XXII, p. 93. 
los últimos años habían sido habituales los navíos del norte de Europa en el puerto de Cádiz, con cargas de hierro extranjero. No obstante, en las probanzas presentadas por Vizcaya, los testigos aseguraban que los extranjeros seguían cargando hierro vasco para los retornos; el hierro de Vizcaya y Guipúzcoa se comercializaba en aquellas fechas sobre todo en Francia y Castilla la Vieja, además de en Indias. Sin embargo, no tenía ya tanta salida a Inglaterra, puesto que como afirmaba Guipúzcoa, “...aplicandose aquella advertida y reparada Nacion a comprar lo mejor, aunque mas caro, puesto que no tenga igual salida para Inglaterra, por ser insoportable el gravamen del dacio, que se cobra en aquel Reyno, de todo fierro de España...". Según datos que aporta la Real Orden decretada por Carlos II en mayo de 1675 para que el gobernador de Cádiz hiciese pesquisa del hierro extranjero, existían más de 40.000 quintales de hierro en Cádiz y Sevilla, procedentes de Lieja, Francia y otras partes del norte de Europa ${ }^{98}$. Todavía en 1698 las Juntas Generales de Guipúzcoa solicitaban medidas contra la libre circulación de hierro sueco y alemán (Lieja) en Andalucía. En 1699 los comisionados de Vizcaya y Guipúzcoa celebraron un congreso en Durango en el que acordaron solicitar al rey el permiso para establecer Jueces Conservadores en Cádiz y Sevilla, revestidos de privativa jurisdicción en el comercio del hierro, y guardas en las flotas y navíos de registro, destinados al decomiso de hierro extranjero ${ }^{99}$. En 17011702 se seguía denunciando la introducción de hierro, a pesar de las prohibiciones. Se había optado por marcar el hierro, cambiando periódicamente el símbolo, pero los extranjeros los falsificaban y comerciaban de bordo a bordo, sin pisar tierra. Finalmente, con el advenimiento de la dinastía borbónica, una Real Orden de 1702 obligó a registrar el hierro en Cádiz, aunque saliese por Cádiz, Sanlúcar y Sevilla, ante un Juez oficial de la Casa de Contratación, cuyo salario sería abonado por Vizcaya, Guipúzcoa y demás interesadas ${ }^{100}$.

Durante este segundo período también se intentó obstaculizar la entrada de hierro navarro, y de esa forma en la Junta de Cestona celebrada en 1685 se impuso la obligación de manifestarlo en los pueblos guipuzcoanos limítrofes, siendo embargados en caso de no tener póliza, y un canon de medio real de plata por cada quintal por razón de alcabala, aunque los navarros contaban con reales órdenes que únicamente les obligaban a pagar 6 maravedís por quintal, lo cual generó las protestas de las villas ferronas y limítrofes navarras (Lesaca, Vera, Echalar, Aranaz, Yanci, Goizueta, Leiza, Areso y Arano ${ }^{101}$.

98 AGG-GAO, JD IM 2/21/32.

99 AGG-GAO, JD AJF, Fotocopias 7,17 y GonZÁLEZ GonZÁlEZ: op.cit., (nota 3), pp. 209-210.

${ }_{100}$ AGG-GAO, JD IM 2/21/38. Téngase en cuenta que el advenimiento de Felipe V, hizo del Imperio Habsbúrgico un enemigo de España, lo que cerró sus puertas al hierro de Lieja, o cuando menos hizo que no tuviese un trato preferencial, como procedente de un país aliado.

${ }^{101}$ AGG-GAO, JD IM 2/21/36. 


\section{EL AUMENTO DE LA PRODUCTIVIDAD Y LA MEJORA DE LOS RENDIMIENTOS}

En 1662 el licenciado Arnedo denunciaba que los particulares no respetaban la obligación de dejar horca y pendón en los jarales y llamaba la atención ante el corregidor sobre el aumento del consumo de carbón por parte de las ferrerías situadas en los montes francos del Urumea. De las 13 ferrerías existentes, 6 permanecían labrantes y 7 no trabajaban; sin embargo, dichas ferrerías habían aumentado su productividad, pasando de producir 20 o 30 quintales a labrar 50 o 60 quintales, duplicando así mismo el consumo de carbón, esto es, de unos 1.500-1.600 quintales a 2.700-3.000 quintales de hierro. Según los mismos testimonios los montes, jarales de roble y avellano en su gran mayoría, producían menos carbón que antaño, pues si anteriormente aportaban unas 2.000 o 3.000 cargas, ahora únicamente contribuían con una tercera parte. La razón señalada era que como consecuencia de que de un corte a otro transcurrían unos veinte años, los pies de los robles engordaban en exceso y la tala de pie grueso hacía perder el monte, pues aunque el primer corte daba mucho producto y carbón, posteriormente los renuevos tardaban largos períodos en brotar. También hubo de repercutir en ello el retroceso del bosque a consecuencia de la expansión de las rozaduras y terrenos de labor, desde la década de los años treinta del siglo XVII, y el encarecimiento de la leña que, según Arnedo, había pasado de valer medio real de plata en 1628 a real y medio en $1662^{102}$. El mencionado descenso de la productividad forestal está detrás de la definitiva conversión de los montes jarales en trasmochos, que en el caso concreto de los montes francos del Urumea se produjo entre 1652 y $1671^{103}$.

Vamos a tratar de racionalizar el baile de cifras que sobre la evolución de la producción aportan los diferentes autores. Díez de Salazar sitúa la producción global de las ferrerías guipuzcoanas en torno a los 100.000-137.500 quintales, es decir, 7.000$10.000 \mathrm{Tm}^{104}$. Según Luis María Bilbao el óptimo de producción en el siglo XV se situaría en torno a los 9.000 y $11.000 \mathrm{Tm}$, mientras que en el siglo XVI pudo alcanzar de 11.000 a $13.000 \mathrm{Tm}$, lo que supondría $33-40 \mathrm{Tm}$ por ferrería para la primera centuria y 40-45 Tm por ferrería para el segundo período, siendo de 45-55 Tm por ferrería para el siglo XVIII. Este autor sitúa la producción de las ferrerías vasconavarras a fines del siglo XVI en 6.000-7.000 Tm ${ }^{105}$. Por su parte, Pablo Fernández de Albaladejo propone para Vizcaya una producción de 47.500 quintales a comienzos del siglo XV y unos 116.600 quintales a finales, y coincide con Fernández de Pinedo en establecer el clímax hacia 1560 con una producción de 140.000-180.000 quintales; este autor considera que los datos señalan una productividad ligeramente superior para Guipúzcoa, puesto que para 1581, según información realizada por las propias instituciones provinciales, las ferrerías guipuzcoanas producirían entre 150.000 y 200.000 quin-

\footnotetext{
102 AMH, C, 5, I, 3, 4.

103 Aragón Ruano: op.cit., (nota 41), pp. 40-43.

104 Díez de Salazar, op.cit., (nota 10), pp. 273-274.

105 Bilbao: op.cit., (nota 3), pp. 51 y 53.
} 
tales $^{106}$. Para 1689 la producción se situó en torno a los 100.000 quintales ${ }^{107}$, lo cual lleva a Fernández Albaladejo a establecer el descenso de la producción global en un $25-50 \%$ a lo largo del siglo XVII: de los 96.000 quintales de producción global, las ferrerías de la cuenca del Deva producían 12.000 quintales, las del Urola 24.000, las del Oria 11.000, las del Urumea 34.000 y las de Rentería 15.000; estos datos, que dan a la cuenca del río Urumea las cotas más altas de la provincia vendrían a corroborar las afirmaciones del licenciado Arnedo. Curiosamente, Fernández Albaladejo afirma que el sector industrial fue marginado en aras de la exportación de mineral en bruto o escasamente elaborado, cuando el mencionado memorial redactado por Antonio de Garaio en 1689 afirmaba que al menos un tercio de la producción eran rejas, herraje, clavos, llantas y otros productos elaborados ${ }^{108}$. Más aún, los datos que aporta sobre la evolución de la producción individual de cada ferrería, lejos de mostrar una bajada, muestran un ascenso: para 1625-1640 sitúa la producción en torno a los 1.000 quintales, desde 1640 en 2.200 quintales y para 1688 en 2.500 quintales, aunque advierte de que son producciones óptimas y no medias ${ }^{109}$.

La documentación por nosotros consultada nos lleva a reafirmar que durante la segunda mitad del siglo XVI y durante todo el siglo XVII se llegó a las más altas cotas de producción en comparación con las que se había obtenido hasta entonces en los siglos XV y XVI y las que se conseguirían posteriormente durante el siglo XVIII ${ }^{110}$. La escasez de documentación hace muy difícil y complicado calcular la producción global de las ferrerías guipuzcoanas durante el siglo XVII. Podemos estar de acuerdo en que se produjo una disminución en el número de instalaciones, que en todo caso sería mucho menor de lo que el memorial de 1689 manifiesta, toda vez que dicho documento pretendía dibujar una situación caótica del sector, para de esa forma obtener el apoyo de la corona con motivo de la prohibición establecida por Vizcaya para

106 FernÁndez Albaladejo: op.cit., (nota 3), pp. 53-55.

107 Ibidem, pp. 60-61. Alfonso González Gonzalez estima la producción total en 81 quintales, aunque se olvida de incluir la producción de las ferrerías de la cuenca del río Oyarzun. GONZÁLEZ GONZÁLEZ, op.cit., (nota 3), pp. 250-252.

108 AGG-GAO, JD IM 1/13/29. De todas formas, hemos detectado algunas ausencias en la lista de ferrerías que se mencionan en el mismo, por lo que tanto el número de ferrerías como la producción deben considerarse al alza.

109 Fernández Albaladejo: op.cit., (nota 3), pp. 60-61, nota núm. 97.

110 Existen, en principio, dos fórmulas para conocer la producción individual de las ferrerías guipuzcoanas. La primera de ellas son los testimonios directos, a través de las probanzas de pleitos o memoriales, más fiables en caso de que sean aportados por los propios operarios. A pesar de contar con numerosos datos, desgraciadamente aparecen aislados y no pueden ser comparados cronológicamente, por lo que se ha renunciado a su uso, al menos momentáneamente. En segundo lugar están los situados sobre la albalá y diezmo viejo de las ferrerías. Únicamente en aquellos pleitos surgidos por el impago de derechos suelen aparecer las producciones particularizadas. En el caso de contar únicamente con la cuantía de los derechos cobrados, es muy peligroso -y por ello mismo no hemos hecho uso de dicha fuente- aplicar el valor de 3'5 maravedís por cada quintal de hierro labrado, que es lo que los titulares de dichos derechos cobraban, puesto que dicha cuantía tendió a fosilizarse, a pesar de la reducción y desaparición del número de instalaciones, como ocurre por ejemplo en las ferrerías de la cuenca del río Bidasoa hacia 1604. AGG-GAO, CO LEJ 176. 
exportar vena de Somorrostro ${ }^{111}$. Pero la reorganización del sector, provocada por las numerosas y continuadas innovaciones introducidas en el mismo (martinetes, sistema a la genovesa, diversificación en ferrerías mayores y menores, aparición de instalaciones integrales, primero mayores, luego pequeñas y finalmente, nuevas ferrerías), realidad ignorada por gran parte de la historiografía ${ }^{112}$, provocó la desaparición de algunas ferrerías, seguramente las más débiles y con mayores inconvenientes geográficos y de emplazamiento, y sobreviviendo las más fuertes, las de mayor capacidad financiera, las que adoptaron un modelo integral y de concentración de las instalaciones, las cuales pudieron desde ese momento disfrutar de una menor competencia y una mayor cuota de mercado, que les permitió y obligó a aumentar la productividad.

Díez de Salazar sitúa la producción media de cada ferrería en 1.000-1.200 quintales para finales del siglo XV y la primera mitad del siglo XVI, mientras que para la segunda mitad del siglo XVI la cifra en torno a los 1.500-1.800 quintales, media que se mantiene atendiendo a los datos aportados por Lope de Isasti, cerca de los 1.500 quintales ${ }^{113}$. Como hemos tenido ocasión de comprobar, Luis María Bilbao reduce considerablemente esas cantidades, estableciendo medias en torno a 400-500 quintales para el siglo XV, 500-600 quintales para el siglo XVI, siendo en el XVIII de 600-750 quintales ${ }^{114}$. En la tabla 6 podemos comprobar cómo en líneas generales, si comparamos las producciones particulares de cada una de las ferrerías expresadas, la productividad aumenta comparativamente entre el siglo XVI y el XVII ${ }^{115}$. Un ejemplo claro es el de la ferrería Lasarte, en jurisdicción de San Sebastián, que entre 1534 y 1545 produjo anualmente 700 quintales, mientras que en 1689 había duplicado dicha cifra, produciendo 1.500 quintales. La ferrería de Ugarteola, en Oyarzun, pasó de producir 600 quintales entre $1574-1578$ a los 1.900 quintales entre 1579 y 1588 , muy posiblemente gracias al establecimiento de un martinete, junto a la ferrería mayor, pues para 1630 ya consta en la documentación ${ }^{116}$. En el caso de Aramburu, también en Oyarzun, apreciamos que entre en 1567 producía 960 quintales, mientras que entre 1574 y 1578 pasará a producir entre 500 y 1.200 quintales y entre 1579 y 1588 entre 1.000 y 1.500 quintales. Sabemos que entre 1567 y 1578 era ferrería mayor, pero ya para 1624 las ferrerías de Aramburu eran ferrerías menores con martinete, momento en el que en el contrato de arrendamiento de las mismas se obliga a los arrendatarios a convertirla en ferrería mayor. Todo ello significa que ya entre 1578 y 1588 además de la ferrería mayor se construyó una ferrería menor con martinete; posteriormente,

111 Quizás por ello habla de que se habían dejado de producir 220.000 quintales, lo que había supuesto unas pérdidas en el sector de 1.000.000 de escudos.

112 Fernández Albaladejo ya manifiesta su convencimiento de que “...el descenso de producción se compensó a expensas de la supervivencia de las ferrerías mejores únicas que introdujeron innovaciones técnicas. ". Fernández Albaladejo: op.cit., (nota 3), p. 60.

113 DíEz de Salazar: op.cit., (nota 10), pp. 273-273.

114 BilbaO: op.cit., (nota 3), pp. 51 y 53. Se toma como referencia que 1 quintal de hierro macho tiene 150 libras y que cada una de ellas equivale a 0’492 kg. CArrión Arregui, I. M.: “Los antiguos pesos y medidas guipuzcoanos", Vasconia, 24 (1996), pp. 72-78.

115 Díez de Salazar ya advertía que “... a medida que rebasamos el siglo XVI la producción va en aumento...". DíEz DE SALAZAR: op.cit., (nota 10), p. 273.

116 AMR, E,7,III,3,1. 
en ese mismo período, la ferrería mayor se convertiría en ferrería menor, dando lugar a las dos ferrerías menores que se mencionan en $1624^{117}$.

Un caso ilustrativo es el de la cuenca media del Urola, entre Azpeitia y Cestona, donde, si bien en 1551 existían activas diez ferrerías (las tres de Herarrieta, Bedama, Chiriboga, Lasao, Alzolaras de Arriba, Alzolaras de Abajo, Iraeta, y Lilii ${ }^{118}$ ), hacia 1590 se habían reducido a ocho y para 1600-1601 sólo funcionaban cuatro (Iraeta, Lili, la de Ochoa de Arrona, en Arrona, y la de Isurola de Suso en Cestona, en el valle de Lili), estando el resto "germadas" e inactivas (Isurola de Yuso, en Azpeitia, la ferrería de Juan Pérez de Loyola, en el río Bedua, y la de Rodrigo de Sasiola). Lope Martínez de Isasti menciona en 1625 a Alzolaras, Iraeta y Lasao con martinete ${ }^{119}$. No obstante, lo que más nos interesa es la producción de cada una de ellas. Según testimonio del Corregidor -que concuerda con los testimonios de los testigos-, entre todas producían 3.200 quintales anuales, de 150 libras cada quintal: la ferrería mayor de Iraeta producía 1.800 quintales anuales, la de Lili 600-700 quintales, la de Arrona 500-600 quintales e Isurola de Suso 300 quintales ${ }^{120}$. Pues bien, según Ignacio Carrión $^{121}$, en el siglo XVIII las tres ferrerías mayores de Iraeta producían 3.200 quintales (una media de 1.066 quintales anuales cada una de ellas) y Lili 500 quintales. Más aún, en el caso de las anteriormente mencionadas ferrerías de Agaraiz, en Villabona, si en 1621 producían entre 1.500 y 1.800 quintales anuales, en el siglo XVIII -según el mencionado autor- únicamente alcanzaban los 800 quintales. Otro tanto ocurre con la ferrería de Lasarte, que entre 1739 y 1745 tuvo una producción media de 769 quintales, cuando en 1689 era de 1.500 quintales, o Barrenola ${ }^{122}$, en Azpeitia, que producía 1.400 quintales entre 1626-1627, mientras que en el XVIII cubre una media de 1.100 quintales. Podríamos prodigarnos con los ejemplos, pero creemos que ha quedado suficientemente probado que el siglo XVII es el período en el que las ferrerías guipuzcoanas alcanzaron su máximo de productividad.

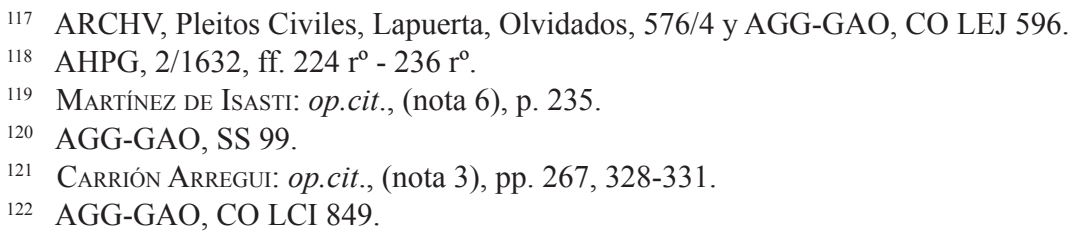


6. Tabla: Producción de las ferrerías guipuzcoanas durante los siglos XVI y XVII ${ }^{123}$

\begin{tabular}{|c|c|c|c|}
\hline Cuenca & Ferrería & Fecha & $\begin{array}{l}\text { Producción } \\
\text { (quintales) }\end{array}$ \\
\hline \multirow{15}{*}{ Oyarzun } & \multirow{2}{*}{ Ferrerías de Oyarzun } & 1508 & 1.000 \\
\hline & & $1603-1605$ & 1.700 \\
\hline & \multirow{3}{*}{ Aramburu (Oyarzun) } & 1567 & 960 \\
\hline & & $1574-1578$ & $500-1.200$ \\
\hline & & $1579-1588$ & $1.000-1.500$ \\
\hline & Olaizola (Oyarzun) & 1567 & $1.200-1.620$ \\
\hline & Fagoaga (Oyarzun) & $1562-1588$ & 1.500 \\
\hline & \multirow{2}{*}{ Zuaznabar (Oyarzun) } & $1574-1586$ & 800 \\
\hline & & $1587-1588$ & 1.300 \\
\hline & \multirow{2}{*}{ Yurrita (Oyarzun) } & $1574-1578$ & $1.400-1.500$ \\
\hline & & $1582-1588$ & 1.200 \\
\hline & \multirow{3}{*}{ Ugarteola (Oyarzun) } & $1574-1578$ & 600 \\
\hline & & $1579-1583$ & 1.000 \\
\hline & & $1584-1588$ & 1.900 \\
\hline & Renteriola (Rentería) & 1599 & $1.400-1.800$ \\
\hline \multirow{4}{*}{ Leizarán } & \multirow{2}{*}{ Ferrerías de Leizarán } & 1540 & 600 \\
\hline & & 1570 & 1.000 \\
\hline & Olloquiegui (Berástegui y & 1550 & 530 \\
\hline & Elduayen) & 1570 & 930 \\
\hline \multirow{8}{*}{ Urola } & Iraeta (Cestona) & \multirow{4}{*}{$1599-1600$} & 1.800 \\
\hline & Lili (Cestona) & & $600-700$ \\
\hline & Arrona (Cestona) & & $500-600$ \\
\hline & Isurola de suso (Cestona) & & 300 \\
\hline & \multirow{4}{*}{ Iguereta (Azpeitia) } & 1677 & 989'5 \\
\hline & & 1679 & 836 \\
\hline & & 1680 & 734 \\
\hline & & 1682 & 1.455 \\
\hline \multirow{2}{*}{ Oria } & \multirow{2}{*}{ Lasarte (San Sebastián) } & $1534-1545$ & 700 \\
\hline & & 1689 & 1.500 \\
\hline
\end{tabular}

123 Díez De Salazar: op.cit., (nota 10), pp., 270 y 269; AGG-GAO, CO ECI 108; AGG-GAO, CO ECI 185; ARCHV, Pleitos Civiles, Lapuerta, Olvidados, 576/4; AGG-GAO, CO LEJ 164; AML, 177/1; AGG-GAO CO MCI 1832; AGG-GAO, CO LCI 1497; AMAz, 595-08; AGG-GAO, CO LEJ 26 y AGG-GAO JD IM 1/13/29. 
Desgraciadamente, no contamos con datos para la segunda mitad, pero si hacemos caso del testimonio del licenciado Arnedo, la productividad subió por encima de las cifras aportadas, aunque suponemos que el fenómeno no sería generalizado. Lo cierto es que manejar medias es complicado, cuando no peligroso, aunque por ello mismo deben ser meramente orientativas; de todas formas, sería mejor trabajar con producciones máximas y óptimas. La variedad de producciones semanales era importante y la documentación nos aporta una serie de casos muy ilustrativos. En 1567 Juanes de Alcibia, arrendador de la ferrería de Olaizola aseguraba que la producción semanal podía ser de 20 a 35 quintales ${ }^{124}$. En la ferrería de Arrazola, en Vizcaya, en 1665, se labraban semanalmente de 20 a 40 quintales, de 155 libras $^{125}$. La ferrería de Iguereta en 1677 labró de 13 a 56 quintales, y en 1679 de 20 a 51 quintales ${ }^{126}$. Las razones de tan dispares cifras hay que buscarlas en el abastecimiento de materias primas, descalabros provocados por la meteorología, reparación de miembros, etc.

\section{CONCLUSIONES}

Durante los siglos XVI y XVII la actividad siderúrgica hubo de enfrentarse a un sinfín de obstáculos y dificultades, aunque con una gran variedad cronológica, geográfica y sectorial. Quizás el momento más complicado que vivió la actividad, al igual que otras del sector secundario, fue la década de los años treinta: el alza de precios, derivado de las devaluaciones monetarias y de las malas cosechas provocadas por condicionantes climáticos, pero también la insistente presión fiscal de una corona inmersa en una costosa política de prestigio, pusieron en peligro la competitividad de los productos siderúrgicos vascos, mientras que la guerra entre Francia y España provocó importantes problemas en la actividad productiva y comercial de la zona cantábrica. A pesar del discurso catastrofista -aunque interesado- de las instituciones guipuzcoanas, el hierro guipuzcoano -y vizcaíno- se siguió exportando a los mercados europeos. Es cierto que las reformas experimentadas por el sector dieron lugar a una disminución en el número de instalaciones, algo por otro lado lógico en mercados tan pequeños y de tan fuerte competencia, pero ello no significó una contracción de la actividad, sino una reorganización: se redujo el número de unidades de producción pero, en compensación, se aumentaron los rendimientos. Ello fue posible gracias tanto a pequeños cambios y ajustes tecnológicos como a la reorganización de la estructura productiva. De un mapa de ferrerías sin especializar, se pasó a uno de ferrerías mayores y menores, con martinete, para acabar finalmente adoptando una solución integral, en la que se aunaban las labores de producción en bruto y transformación. Todos estos cambios no se produjeron, por supuesto de forma inmediata, y no estuvieron exentos de fricciones y resistencias, fracasos, éxitos, tentativas y rectificaciones.

\footnotetext{
124 AGG-GAO, CO ECI 108.

125 AZ, 230-2 y 3.

126 AMAz, 595-08.
} 
En definitiva, el siglo XVII fue un período de cambios, no de crisis; el puente entre el siglo XVI y el siglo XVIII. Durante dicha centuria se iniciaron y desarrollaron una serie de cambios, con respecto al anterior siglo, que se convirtieron en constantes durante el siglo XVIII. Al aumento de la presión fiscal y del precio de los bastimentos, los jornales y ciertos materiales, el sector respondió con cambios en el proceso de producción, que se tradujeron en una reducción de los costos -incluso acudiendo a la autosuficiencia, gracias a la creación de las ferrerías-caserío, o liberando mano de obra hacia la agricultura y la ganadería menor- y en un aumento de los rendimientos, la intensificación en la explotación del mineral guipuzcoano y ciertos cambios en la explotación de los bosques, que permitieron al sector seguir siendo competitivo, a pesar del embate de los hierros extranjeros que, a pesar de todo, nunca lucharon por el mismo mercado. Los productos siderúrgicos vascos conservaron su alto prestigio en los mercados europeos y americanos, no sólo por su calidad sino también por sus precios moderados, producto del estancamiento que las rentas y arrendamientos experimentaron durante el período, contribuyendo así a hacer de la actividad siderúrgica un sector atractivo y dinámico. Dicho estancamiento fue producto de los cambios que en el ámbito de la propiedad y la gestión se produjeron desde la década de los años setenta del siglo XVI: el absentismo de los propietarios, la atomización de la propiedad o la irrupción de las máximas mercantiles, representadas por comerciantes y tratantes de hierro, que trataron de hacerse con todas las fases del proceso, desde la producción hasta su llegada a los mercados, más interesados en la comercialización de los productos que en el cobro de rentas, facilitaron el mantenimiento de unas rentas bajas, incluso su fosilización. Las rentas fueron perdiendo valor a medida que el precio del hierro aumentó, lo que al mismo tiempo fue un instrumento clave -muy posiblemente aplicado de forma consciente- para mantener las explotaciones, que generalmente tenían que hacer frente a un sinfín de eventualidades, reparos y reconstrucciones. La actividad siderúrgica siguió siendo atractiva durante todo el siglo XVII -dentro de una estrategia de diversificación de las inversiones, que implicaba la minimización de los riesgos y el trasvase de capitales de una actividad a otra ${ }^{127}$, prueba de lo cual es la construcción de un gran número de ferrerías de nueva planta, su transformación y ampliación, muchas de ellas municipales, las cuales contaban con importantes ventajas comparativas con respecto a las particulares. El comercio de hierro con América -sobre todo ilícito- y Europa, de forma directa o indirecta, supuso la llegada de grandes remesas de capital a las provincias vascas durante todo este período, que ayudaron a su fortalecimiento económico.

127 Aragón Ruano, A.: "La evolución de la economía guipuzcoana en tiempos de Urdaneta: un período de desarrollo y expansión entre supuestas crisis", en Truchuelo García, S. (ed.): Andrés Urdaneta: un hombre moderno, Ordicia, Ayuntamiento de Ordicia, 2009, pp. 119-144. 